SAND75-0522

Unlimited Release

\title{
Transient Response of Three-Layered Rings
}

Mathias J. Sagartz

Prepared by Sandia Laboratories, Albuquerque New Mexico 87115

and Livarmore. California 94550 for the United Statis Energy Riesearch

and Davelooment Administration under Contract AT 129.1) 789

Printed February 1975

\section{Sandia Laboratories}

When printing a copy of any digitized SAND

Report, you are required to update the markings to current standards. 
Issued by Sandia Laboratories, operated for the United States Energy Research and Development Administration by Sandia Corporation.

\section{NOTICE}

This report was prepared as an account of work sponsored by the United States Government. Neither the United States nor the United States Energy Research and Development Administration, nor any of their emplayees, nor any of their contractors, subcontractors, or their employees, makes any warranty, express or implied, or assumes any legal liability or responsibility for the accuracy, completeness or usefulness of any information, apparatus, product or process disclosed, or represents that its use would not infringe privately owned rights. 
SAND75-0522

Unlimited Release

Printed February 1976

TRANSIENT RESPONSE OF THREE-LAYERED RINGS

Mathias J. Sagartz

Simulation Division, 5233

Sandia Laboratories

Albuquerque, NM

\begin{abstract}
Hamilton's principle is used to derive equations of motion for a linear elastic three-layered ring. The theory includes the effects of shear deformation and rotatory inertia in each layer and radial strain effects in the middle layer. A convenient computational technique is developed for transient response evaluation without resorting to finite-difference or finite-element approximations. A companion experimental study was conducted using three different rings. All rings had aluminum inner and outer layers, but each had a different low-modulus middle layer. Radial impulse loads, axisymmetric and distributed as a cosine over half the ring circumference, were applied to the outer ring surface, and the transient response was monitored with strain gages mounted on the aluminum layers. Measured strain-time histories were compared with theoretical calculations, and good agreement was obtained.
\end{abstract}

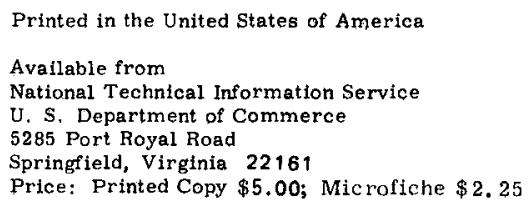




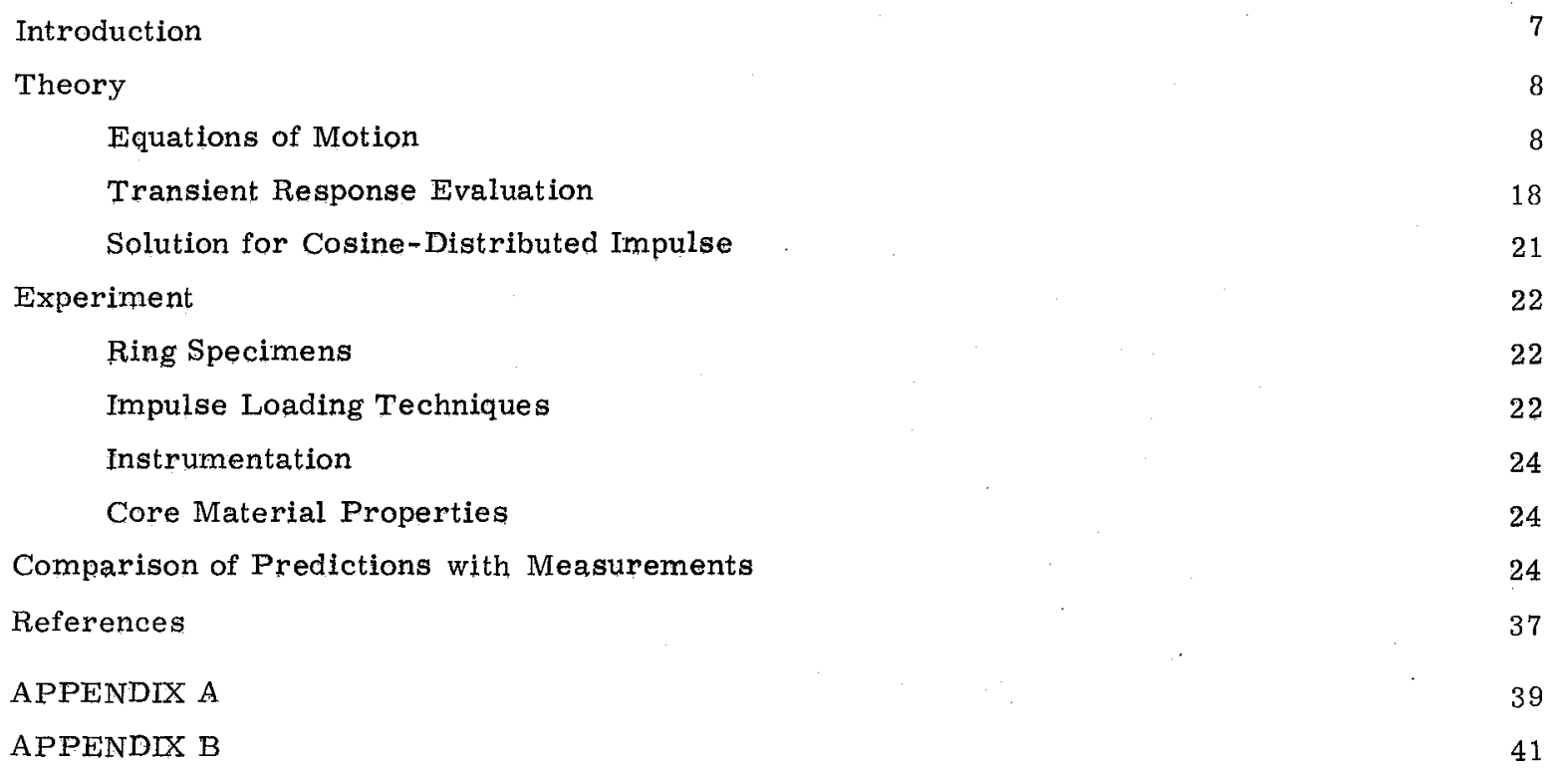

\section{ILLUST RATIONS}

Figure

1 Geometry

2 Displacements $\quad 10$

3 Experimental Setups $\quad 23$

4 Long Time Strain Response $\quad 25$

$5 \quad$ Strain vs Time for Ring with $12 \mathrm{Lb} / \mathrm{Ft}^{3}$ Foam Core 26

6 Strain vs Time at $\theta=180^{\circ}$ for Ring with $12 \mathrm{Lb} / \mathrm{Ft}^{3}$ Foam Core

7 Strain vs Time at $\theta=180^{\circ}$ for Ring with $12 \mathrm{Lb} / \mathrm{Ft}^{3}$ Foam Core 28

$8 \quad$ Strain vs Time for Ring with $20 \mathrm{Lb} / \mathrm{Ft}^{3}$ Foam Core $\quad 29$

9 Strain vs Time at $\theta=180^{\circ}$ for Ring with $20 \mathrm{Lb} / \mathrm{Ft}^{3}$ Core 30

10 Strain vs Time at $\theta=180^{\circ}$ for Ring with $20 \mathrm{Lb} / \mathrm{Ft}^{3}$ Foam Core 31

11 Strain vs Time for Ring with Sylgard Core 32

12 Strain vs Time at $\theta=180^{\circ}$ for the Ring with Sylgard Core 33

13 Strain vs Time at $\theta=180^{\circ}$ for Ring with Sylgard Core 34 
TRANSIENT RESPONSE OF THREE-LAYERED RINGS

Introduction

With the increased use of laminated structural elements, several authors have developed theories for the dynamic analysis of laminated rings and shells. ${ }^{1-11}$ However, the large number - of parameters that appear in the theories, together with the wide range of values these parameters can assume, makes a thorough treatment of this topic extremely difficult. The scope of this report is limited to three-layered composite rings, with particular emphasis on rings whose middle or core layer is very soft in comparison with the other layers.

Most previous work on three-layered shell dynamics has resulted in a series of dispersion curves rather than the solution to any specific transient response problem. The difficulty with a dispersion-type analysis is that some inadequacies in the theory can easily be overlooked. As an example, consider a three-layered shell having a thick, soft core layer, If an impulse of magnitude $I_{o}$ is applied to an element of the outer shell layer, the kinetic energy that goes into structuraltype modes depends on the core radial displacement assumption. If the core is radially rigid, the energy is $I_{0}^{2} / 2\left(m_{0}+m_{i}+m_{c}\right)$, but if the core can strain radially, the energy is $I_{0}^{2} / 2 m_{0^{*}}$ Here the $\mathrm{m}^{\prime} \mathrm{s}$ are the masses of the different layers of the shell element and $i, o$, and $c$ stand for the inner, outer, and core layers, respectively. This discrepancy in energies can lead to significant differences in calculated strains. As another example, consider the limiting case of rigid inner and outer layers and a nonaxisymmetric radial impulse applied to the outer layer. The ring translates as a rigid body, but a vibration is superimposed on the translation because the rigid layers are connected by an elastic core. Any theory that does not allow both shear and radial strain in the core does not account for this vibration and cannot accurately give the ring displacements or accelerations.

Unfortunately, most previous work on three-layered rings and shells has not included experimental data. Since the range of validity for many of the assumptions used in the theories is not well established, such data are valuable. To help fill this need, strain -time response data for impulse loaded three-layered rings is included in this report and comparison with predictions is presented. 
Equations of Motion

The three-layered ring shown in Figure 1 is referred to the modified set of polar coordinates, $z$ and $\theta$, where $z$ is measured radially outward from the interface between the outer and core layers. Subscripts $i, o$, and $c$ are used to designate properties belonging to inner, outer, and core layers, respectively. Young's modulus, shear modulus, density, and thickness are denoted by $E$, G, $\rho$, and $h$; and, for example, $G_{i}$ is the shear modulus of the inner layer. Time is denoted by $t$ and $R$ is the radius to the reference surface where $z=0$. A linear elastic stress-strain relation is used for the outer and inner layers,

$$
\sigma_{\theta}=\mathrm{E}_{\alpha{ }^{\epsilon} \theta} ; \tau_{\mathrm{z} \theta}=\mathrm{G}_{\alpha \mathrm{z \theta}}, \quad \alpha=\mathrm{i}, \mathrm{o}
$$

where $\sigma_{\theta}$ and $\epsilon_{\theta}$ are the circumferential stress and strain; whereas $\tau_{z \theta}$ and $\gamma_{z \theta}$ are the shear stress and strain. The core layer is assumed to obey the orthotropic stress-strain law

$$
\begin{aligned}
& \sigma_{\theta}=c_{1} \epsilon_{\theta}+c_{3} \epsilon_{z} \\
& \sigma_{z}=c_{3} \epsilon_{\theta}+c_{2} \epsilon_{z} \\
& \tau_{z \theta}=c_{4} \gamma_{z \theta},
\end{aligned}
$$

where $\sigma_{z}$ and $\epsilon_{z}$ are radial stress and strain. As implied by the above stress-strain relations, the effects of radial strain are included only in the core layer.

The theory formulated herein is a structural-type theory, and the displacements in the cross section are piecewise linear functions of $z$. Eight displacement functions are used to specify the position of a cross section; $w_{o}, w_{i}$, and $w_{c}$ are the radially outward displacements of the outer and inner layers and at the center of the core layer; $\phi_{0}$ and $\phi_{i}$ are the angles of rotation of normals for the outer and inner layers and $v_{0}, v_{i}$, and $v_{c}$ are a measure of circumferential displacements. It should be noted, as shown in Figure 2, that $v_{o}$ and $v_{i}$ are not the circumferential displacements at the middle of their respective layers. In terms of these displacement functions, the strains in the outer and inner layers are

$$
\begin{aligned}
& \epsilon_{\theta}=\frac{w_{\alpha}}{R(1+z / R)}+\frac{1}{R(1+z / R)}\left(\frac{\partial v_{\alpha}}{\partial \theta}+z \frac{\partial \phi}{\partial \theta}\right) \\
& \gamma_{z \theta}=\frac{1}{R(1+z / R)}\left[\frac{\partial w}{\partial \theta}-v_{\alpha}-z \phi \alpha\right]
\end{aligned}
$$




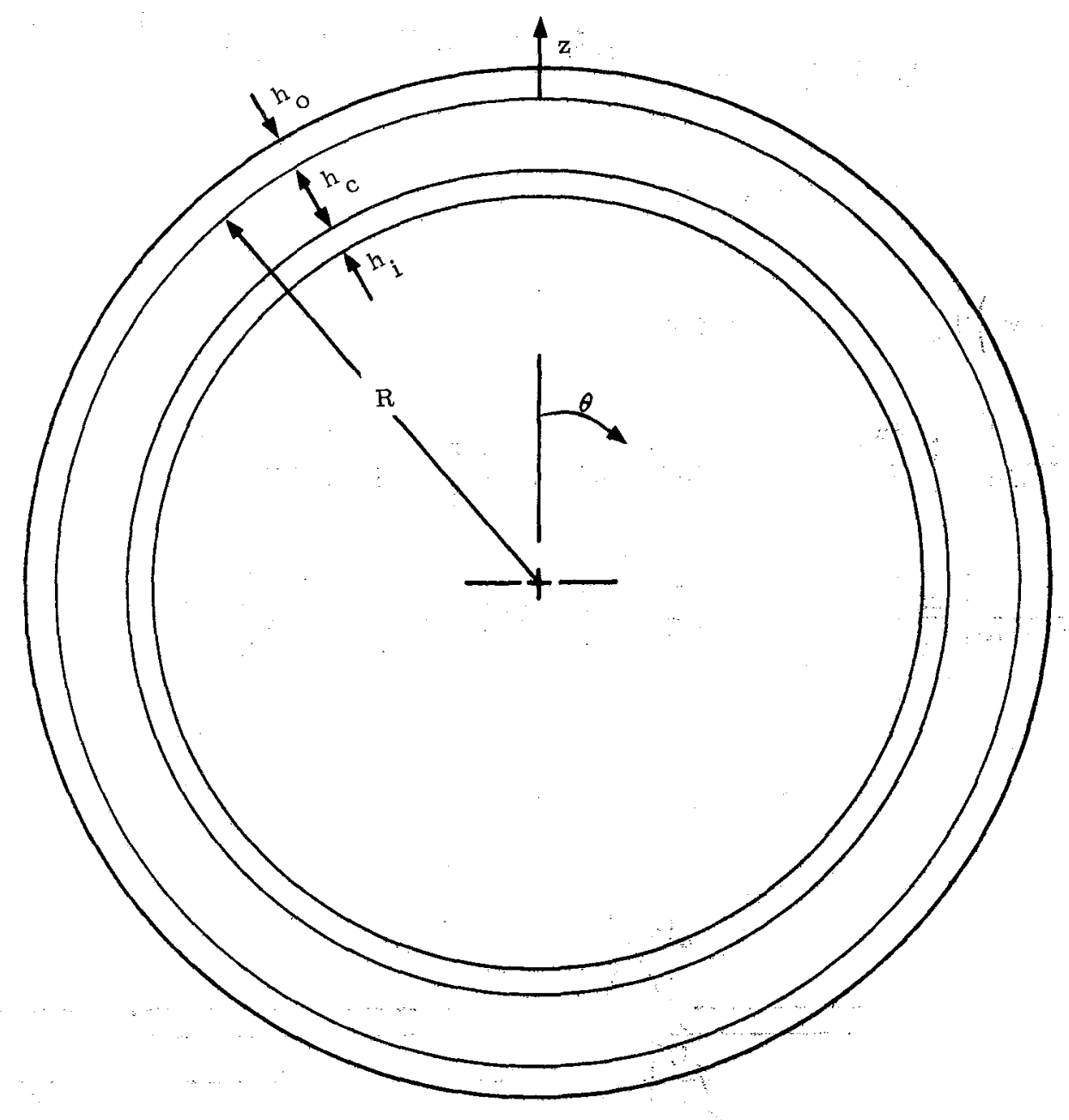

Figure 1. Geometry 
and with $\zeta=z+h / 2$, the core strains are

$\epsilon_{\theta}= \begin{cases}\frac{1}{R(1+z / R)}\left[w_{c}+\frac{2 \zeta}{h_{c}}\left(w_{o}-w_{c}\right)+2 \frac{\zeta}{h_{c}} \frac{\partial v_{o}}{\partial \theta}+\left(1-\frac{2 \zeta}{h_{c}}\right) \frac{\partial v_{c}}{\partial \theta}\right] & 0<\zeta<h_{c} / 2 \\ \frac{1}{R(1+z / R)}\left[-2 \frac{\zeta}{h_{c}} w_{i}+\left(1+2 \frac{\zeta}{h_{c}}\right) w_{c}-2 \frac{\zeta}{h_{c}} \frac{\partial v_{i}}{\partial \theta}+2 \zeta \frac{\partial \phi_{i}}{\partial \theta}+\left(1+2 \frac{\zeta}{h_{c}}\right) \frac{\partial v_{c}}{\partial \theta}\right] & \frac{-h_{c}}{2}<\zeta<0\end{cases}$

$\epsilon_{z}= \begin{cases}2\left(w_{0}-w_{c}\right) / h_{c} & 0<\zeta<\frac{h_{c}}{2} \\ 2\left(w_{c}-w_{i}\right) / h_{c} & -h_{c}<\zeta<0\end{cases}$

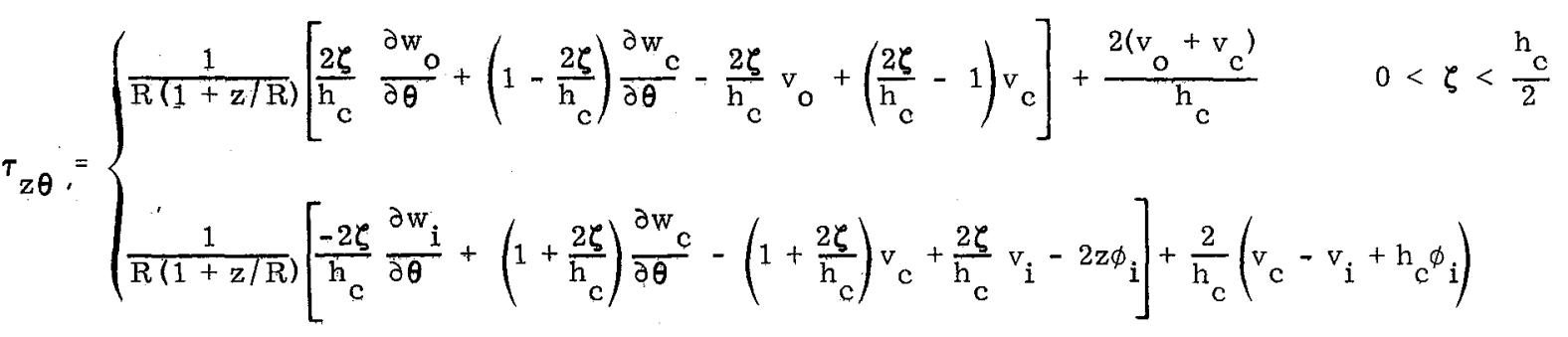

$\frac{-h_{c}}{2}<\zeta<0$

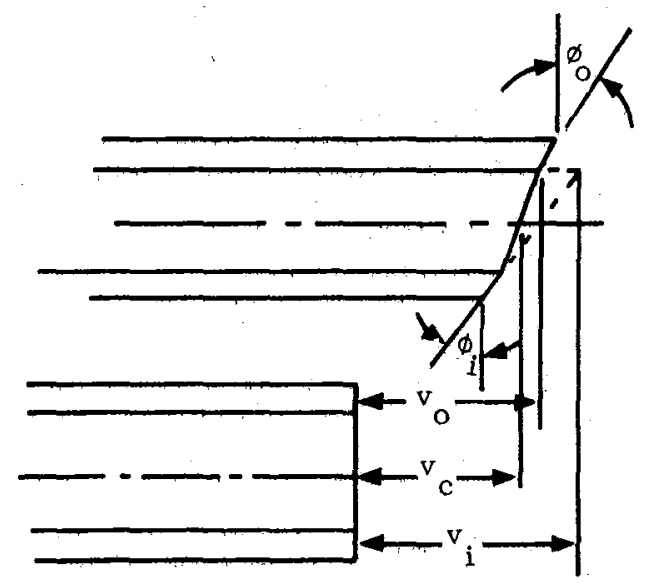

Circumferential

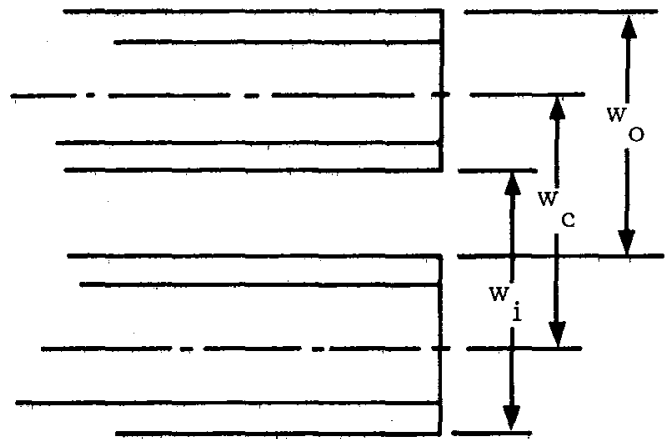

Radial

Figure 2. Displacements 
The potential energy $U$ is

$$
\begin{aligned}
U=\frac{1}{2} \int_{0}^{2 \pi} & \left\{\int_{0}^{h_{0}}\left[E_{0} \epsilon_{\theta}^{2}+G_{0} \gamma_{z \theta}^{2}\right] R(1+z / R) d z\right. \\
& +\int_{-h_{c}-h_{i}}^{-h}\left[E_{i} \epsilon_{\theta}^{2}+G_{i} \gamma_{z \theta}^{2}\right] R(1+z / R) d z \\
& \left.+\int_{-h_{c}}^{o}\left[c_{1} \epsilon_{\theta}^{2}+c_{2} \epsilon_{z}^{2}+2 c_{3} \epsilon_{z} \epsilon_{\theta}+c_{4} \gamma_{z \theta}^{2}\right] R(1+z / R) d z\right\} d \theta
\end{aligned}
$$

and the kinetic energy $\mathrm{T}$ is

$$
\begin{aligned}
& T=\int_{0}^{2 \pi}\left\{\frac{\rho_{0}}{2} \int_{0}^{h_{0}}\left[\dot{\mathrm{w}}_{0}^{2}+\left(\dot{\mathrm{v}}_{\mathrm{o}}+\mathrm{z} \dot{\phi}_{0}\right)^{2}\right] R(1+\mathrm{z} / \mathrm{R}) \mathrm{dz}\right. \\
& +\frac{\rho_{i}}{2} \int_{-h_{c}-h_{i}}^{-h_{c}}\left[\dot{w}_{i}^{2}+\left(\dot{v}_{\dot{i}}+z \dot{\phi}_{i}\right)^{2}\right] R(1+z / R) d z \\
& +\frac{\rho_{c}}{2} \int_{0}^{\frac{h_{c}}{2}}\left\langle\left[\left(1-\frac{2 \zeta}{h_{c}}\right) \dot{w}_{c}+\frac{2 \zeta}{h_{c}} \dot{w}_{o}\right]^{2}+\left[\left(1+2 \frac{\zeta}{h_{c}}\right) \dot{v}_{c}+\frac{2 \zeta}{h_{c}} \dot{v}_{o}\right]^{2}\right\rangle\left(R-\frac{h_{c}}{2}\right)\left(1+\frac{\zeta}{R}\right) d \zeta \\
& \left.+\frac{\rho c}{2} \int_{\frac{-h_{c}}{2}}^{0}\left\langle\left[\left(1+\frac{2 \zeta}{h_{c}}\right) \dot{w}_{c}-\frac{2 \zeta}{h_{c}} \dot{w}_{i}\right]^{2}+\left[\left(1+\frac{2 \zeta}{h_{c}}\right) \dot{v}_{c}+2 \zeta \dot{\phi}_{i}-\frac{2 \zeta}{h_{c}} \dot{v}_{i}\right]^{2}\right\rangle\left(R-\frac{h_{c}}{2}\right)\left(1+\frac{\zeta}{R}\right) d \zeta\right\} d \theta
\end{aligned}
$$

With expressions for the kinetic and potential energies established, Hamilton's principle

$$
\delta \int_{t_{1}}^{t_{2}}(T-U) d t=\delta \int_{t_{1}}^{t_{2}} L d t
$$


can be used to derive the equations of motion. In Equation (10), $L$ is the work done by applied loads and $t_{1}$ and $t_{2}$ are arbitrary times. Only tractions on the ring surfaces are considered and

$\delta L=\int_{0}^{2 \pi}\left\langle\left[p_{0} \delta w_{o}+q_{o}\left(\delta v_{o}+h_{c} \delta \phi o\right)\right]\left(1+\frac{h_{c}}{R}\right)+\left\{p_{i} \delta w_{i}+q_{i}\left[\delta v_{i}-\left(h_{c}+h_{i}\right) \delta \phi_{i}\right]\right\}\left(1-\frac{h_{i}+h_{c}}{R}\right)\right\rangle \times R d \theta$

where $p_{0}$ and $p_{i}$ are radial tractions on the outer and inner surfaces and $q_{0}$ and $q_{i}$ are circumferential tractions. These loads are positive if they act in the positive $z$ and $\theta$ directions, respectively.

The equations of motion are derived by first using Equations (3) through (8) to write $U$ in terms of displacements and then substituting this expression along with Equations (9) and (11) for $T$ and $L$ into Equation (10). The resulting Euler-Lagrange equations, given below, are the equations of motion for the three-layered ring. Because strain energy due to shear is included in the potential energy, the theory includes shear deformation effects, and the presence of velocity terms which are functions of $\mathrm{z}$ means rotatory inertia effects are included. 


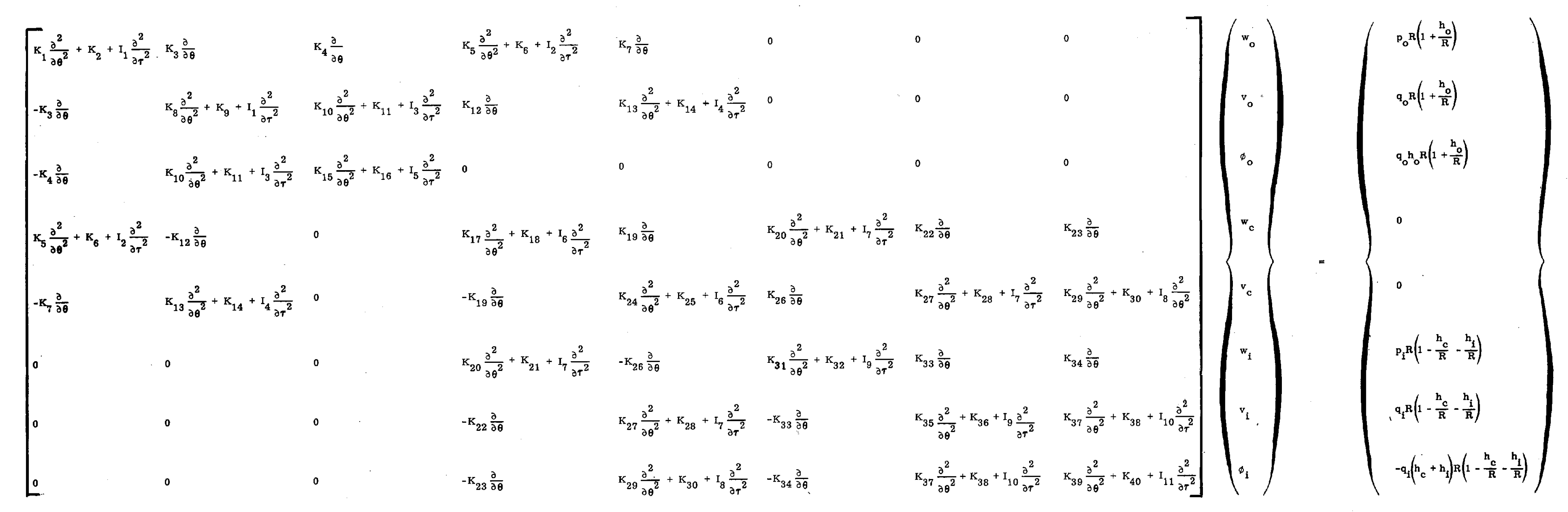




$$
\begin{aligned}
& \mathrm{K}_{1}=\gamma_{\mathrm{o}} \mathrm{k}_{\mathrm{o} 0}-4 \beta \mathrm{t}_{6} \mathrm{c}_{4} \\
& \mathrm{~K}_{2}=-\mathrm{k}_{\mathrm{o} 0}+4 \beta\left(\mathrm{t}_{1} \mathrm{c}_{3}+2 \mathrm{c}_{2} \mathrm{t}_{5}+\mathrm{t}_{6} \mathrm{c}_{1}\right) \\
& \mathrm{K}_{3}=-\mathrm{k}_{\circ 0}-\gamma_{\mathrm{o}} \mathrm{k}_{\mathrm{o} 0}+4 \beta\left[\mathrm{c}_{2} \mathrm{t}_{5}+\mathrm{c}_{1} \mathrm{t}_{6}+\mathrm{c}_{4}\left(\mathrm{t}_{6}-\mathrm{t}_{5}\right)\right] \\
& \mathrm{K}_{4}=-\mathrm{k}_{\mathrm{o} 1}+\gamma_{\mathrm{o}} \mathrm{k}_{\mathrm{o} 0} \\
& K_{5}=-2 \delta c c_{4}\left(t_{4}-2 \delta t_{6}\right) \\
& K_{6}=-4 \beta\left(c_{3} t_{1}+2 c_{2} t_{5}+c_{1} t_{6}\right)+26\left(c_{2} t_{2}+c_{1} t_{4}\right) \\
& K_{7}=-4 \beta\left[c_{2} t_{5}+c_{1} t_{6}+c_{4}\left(t_{6}-t_{5}\right)\right]+2 \delta\left(c_{2} t_{2}+c_{1} t_{4}+c_{4} t_{4}\right) \\
& \mathrm{K}_{8}=\mathrm{k}_{\mathrm{o} 0}^{\prime}-4 \beta \mathrm{c}_{1} \mathrm{t}_{6} \\
& \mathrm{~K}_{9}=-\gamma_{\mathrm{o}} \mathrm{k}_{\mathrm{o} 0}+4 \beta \mathrm{c}_{4}\left(\mathrm{t}_{1}-2 \mathrm{t}_{5}+\mathrm{t}_{6}\right) \\
& \mathrm{K}_{10}=\mathrm{k}_{\mathrm{o} 1} \\
& \mathrm{~K}_{11}=\gamma_{\mathrm{o}} \mathrm{k}_{\mathrm{o} 0} \\
& K_{12}=4 \beta c_{2} t_{5}+2 \delta\left[c_{1}\left(2 \delta t_{6}-t_{4}\right)+c_{4}\left(t_{2}-t_{4}-2 \delta t_{5}+2 \delta t_{6}\right)\right] \\
& \mathrm{K}_{13}=-26 \mathrm{c}_{1}\left(\mathrm{t}_{4}-28 \mathrm{t}_{6}\right) \\
& \mathrm{K}_{14}=2 \delta \mathrm{c}_{4}\left(-\mathrm{t}_{2}-2 \delta \mathrm{t}_{1}+46 \mathrm{t}_{5}+\mathrm{t}_{4}-2 \delta \mathrm{t}_{6}\right) \\
& \mathrm{K}_{15}=\mathrm{k}_{\mathrm{o} 2} \\
& \mathrm{~K}_{16}=-\gamma_{\mathrm{o}} \mathrm{k}_{\mathrm{o} 0} \\
& K_{17}=-c_{4}\left[t_{3}-48 t_{4}+4 \beta t_{6}+b_{3}+4 \delta b_{4}+4 \beta b_{6}\right] \\
& \mathrm{K}_{18}=4 \beta\left[\mathrm{c}_{3} \mathrm{t}_{1}+\mathrm{c}_{1} \mathrm{t}_{6}+\mathrm{c}_{3} \mathrm{~b}_{1}+\mathrm{c}_{1} \mathrm{~b}_{6}\right]+4 \delta \mathrm{c}_{2}\left(2 \delta \mathrm{t}_{5}-\mathrm{t}_{2}+\mathrm{b}_{2}+26 \mathrm{~b}_{5}\right) \\
& +c_{1}\left(t_{3}-4 \delta t_{4}+b_{3}+4 \delta b_{4}\right) \\
& \mathrm{K}_{19}=-2 \delta \mathrm{c}_{2}\left(\mathrm{t}_{2}-2 \delta \mathrm{t}_{5}-\mathrm{b}_{2}-2 \delta \mathrm{b}_{5}\right)+\mathrm{c}_{1}\left(\mathrm{t}_{3}-4 \delta \mathrm{t}_{4}+4 \beta \mathrm{t}_{6}+\mathrm{b}_{3}+4 \delta \mathrm{b}_{4}+4 \beta \mathrm{b}_{6}\right) \\
& +2 \delta c_{4}\left(t_{2}-2 \delta t_{5}-b_{2}-2 \delta b_{5}\right)+c_{4}\left(t_{3}-4 \delta t_{4}+4 \beta t_{6}+b_{3}+4 \delta b_{4}+4 \beta b_{6}\right)
\end{aligned}
$$




$$
\begin{aligned}
& \mathrm{K}_{20}=2 \delta \mathrm{c}_{4}\left(\mathrm{~b}_{4}+2 \delta \mathrm{b}_{6}\right) \\
& \mathrm{K}_{21}=-4 \beta \mathrm{c}_{3} \mathrm{~b}_{1}-2 \delta\left[\mathrm{c}_{2}\left(\mathrm{~b}_{2}+4 \delta \mathrm{b}_{5}\right)+\mathrm{c}_{1}\left(\mathrm{~b}_{4}+2 \delta \mathrm{b}_{6}\right)\right] \\
& \mathrm{K}_{22}=-4 \beta \mathrm{c}_{2} \mathrm{~b}_{5}+2 \delta\left[-\mathrm{c}_{1}\left(\mathrm{~b}_{4}+2 \delta \mathrm{b}_{6}\right)+\mathrm{c}_{4}\left(\mathrm{~b}_{2}+2 \delta \mathrm{b}_{5}-\mathrm{b}_{4}-2 \delta \mathrm{b}_{6}\right)\right] \\
& \mathrm{K}_{23}=4 \delta \mathrm{c}_{2} \mathrm{~b}_{5}+2 \mathrm{c}_{1}\left(\mathrm{~b}_{4}+2 \delta \mathrm{b}_{6}\right)+2 \mathrm{c}_{4}\left(-\mathrm{b}_{2}-2 \delta \mathrm{b}_{5}+\mathrm{b}_{4}+2 \delta \mathrm{b}_{6}\right) \\
& \mathrm{K}_{24}=-\mathrm{c}_{1}\left(\mathrm{t}_{3}-4 \delta \mathrm{t}_{4}+4 \beta \mathrm{t}_{6}+\mathrm{b}_{3}+4 \delta \mathrm{b}_{4}+4 \beta \mathrm{b}_{6}\right) \\
& \mathrm{K}_{25}=\mathrm{c}_{4}\left[4 \beta\left(\mathrm{t}_{1}+\mathrm{t}_{6}\right)+4 \delta\left(\mathrm{t}_{2}-2 \delta \mathrm{t}_{5}-\mathrm{t}_{4}\right)+\mathrm{t}_{3}+4 \beta\left(\mathrm{b}_{1}+\mathrm{b}_{6}\right)+4 \delta\left(-\mathrm{b}_{2}-2 \delta \mathrm{b}_{5}+\mathrm{b}_{4}\right)+\mathrm{b}_{3}\right] \\
& \mathrm{K}_{26}=+2 \delta\left[\mathrm{c}_{2}\left(\mathrm{~b}_{2}+2 \delta \mathrm{b}_{5}\right)+\mathrm{c}_{1}\left(\mathrm{~b}_{4}+2 \delta \mathrm{b}_{6}\right)+\mathrm{c}_{4}\left(\mathrm{~b}_{4}+2 \delta \mathrm{b}_{6}\right)\right]-4 \beta \mathrm{c}_{4} \mathrm{~b}_{5} \\
& \mathrm{~K}_{27}=2 \delta \mathrm{c}_{1}\left(\mathrm{~b}_{4}+2 \delta \mathrm{b}_{6}\right) \\
& \mathrm{K}_{28}=2 \delta \mathrm{c}_{4}\left[-2 \delta \mathrm{b}_{1}+\mathrm{b}_{2}+4 \delta \mathrm{b}_{5}-\mathrm{b}_{4}-2 \delta \mathrm{b}_{6}\right] \\
& K_{29}=-2 c_{1}\left(b_{4}+2 \delta b_{6}\right) \\
& \mathrm{K}_{30}=2 \mathrm{c}_{4}\left[2 \delta \mathrm{b}_{1}-\mathrm{b}_{2}-4 \delta \mathrm{b}_{5}+\mathrm{b}_{4}+2 \delta \mathrm{b}_{6}\right] \\
& \mathrm{K}_{31}=\gamma_{\mathrm{i} i 0} \mathrm{k}_{\mathrm{i}}-4 \beta \mathrm{c}_{4} \mathrm{~b}_{6} \\
& \mathrm{~K}_{32}=-\mathrm{k}_{\mathrm{i} 0}+4 \beta\left(\mathrm{c}_{3} \mathrm{~b}_{1}+2 \mathrm{c}_{2} \mathrm{~b}_{5}+\mathrm{c}_{1} \mathrm{~b}_{6}\right) \\
& \mathrm{K}_{33}=-\left(1+\gamma_{\mathrm{i}}\right) \mathrm{k}_{\mathrm{i} 0}+4 \beta\left[\mathrm{c}_{2} \mathrm{~b}_{5}+\mathrm{c}_{1} \mathrm{~b}_{6}+\mathrm{c}_{4}\left(\mathrm{~b}_{6}-\mathrm{b}_{5}\right)\right] \\
& \mathrm{K}_{34}=\gamma_{\mathrm{i}} \mathrm{k}_{\mathrm{i} 0}-\mathrm{k}_{\mathrm{i} 1}-4 \delta\left[\mathrm{c}_{2} \mathrm{~b}_{5}+\mathrm{c}_{1} \mathrm{~b}_{6}+\mathrm{c}_{4}\left(\mathrm{~b}_{6}-\mathrm{b}_{5}\right)\right] \\
& \mathrm{K}_{35}=\mathrm{k}_{\mathrm{i} 0}-4 \beta \mathrm{c}_{1} \mathrm{~b}_{6} \\
& K_{36}=-\gamma_{i} k_{i 0}+4 \beta c_{4}\left(b_{1}+b_{6}-2 b_{5}\right) \\
& \mathrm{K}_{37}=\mathrm{k}_{\mathrm{i} 1}+48 \mathrm{c}_{1} \mathrm{~b}_{6} \\
& \mathrm{~K}_{38}=\gamma_{\mathrm{i}} \mathrm{k}_{\mathrm{i} 0}-4 \delta \mathrm{c}_{4}\left(\mathrm{~b}_{1}+\mathrm{b}_{6}-2 \mathrm{~b}_{5}\right) \\
& K_{39}=k_{i 2}-4 c_{1} b_{6} \\
& \mathrm{~K}_{40}=-\gamma_{\mathrm{i}} \mathrm{k}_{\mathrm{i} 0}+4 \mathrm{c}_{4}\left(\mathrm{~b}_{1}+\mathrm{b}_{6}-2 \mathrm{~b}_{5}\right)
\end{aligned}
$$

16 


$$
\begin{aligned}
& I_{1}=-I_{o 0}-4 \beta I_{b 2} \\
& I_{2}=-2 \delta\left(I_{b 1}-2 \delta I_{b 2}\right) \\
& I_{3}=-I_{01} \\
& I_{4}=-2 \delta\left(I_{b 1}-2 \delta I_{b 2}\right) \\
& I_{5}=-I_{02} \\
& I_{6}=-I_{b 0}-I_{c 0}-4 \delta\left(I_{c 1}-I_{b 1}\right)-4 \beta\left(I_{b 2}+I_{c 2}\right) \\
& I_{7}=2 \delta\left(I_{c 1}+2 \delta I_{c 2}\right) \\
& I_{8}=-2\left(I_{c 1}+2 \delta I_{c 2}\right) \\
& I_{9}=-I_{i 0}-4 \beta I_{c 2} \\
& I_{10}=-I_{i 1}+4 \delta I_{c 2} \\
& I_{11}=-I_{i 2}-4 I_{c 2} \\
& \text { and } \\
& \tau=t\left(E_{0} / \rho_{0}\right)^{1 / 2} / R \\
& \gamma_{\alpha}=\mathrm{G}_{\alpha} / \mathrm{E}_{\alpha} \quad \alpha=\mathrm{i}, \mathrm{o} \\
& \delta=\mathrm{R} / \mathrm{h}_{\mathrm{c}}-1 / 2 \quad \beta=\delta^{2} \\
& t_{1}=t_{2}\left(1+t_{2} / 2\right) \quad b_{1}=t_{2}\left(1-t_{2} / 2\right) \\
& t_{2}=0.5 h_{c} /\left(R-h_{c} / 2\right) \quad b_{2}=t_{2} \\
& \mathrm{t}_{3}=\ln \left(1+\mathrm{t}_{2}\right) \quad \mathrm{b}_{3}=-\ln \left(1-\mathrm{t}_{2}\right) \\
& \mathrm{t}_{4}=\mathrm{t}_{2}-\mathrm{t}_{3} \quad \mathrm{~b}_{4}=\mathrm{t}_{2}+\mathrm{b}_{3} \\
& t_{5}=t_{2}^{2} / 2 \quad b_{5}=-t_{2}^{2} / 2 \\
& \mathrm{t}_{6}=-\mathrm{t}_{2}+\mathrm{t}_{2}^{2} / 2+\mathrm{t}_{3} \quad \mathrm{~b}_{6}=-\mathrm{t}_{2}-\mathrm{t}_{2}^{2} / 2+\mathrm{b}_{3}
\end{aligned}
$$




$$
\begin{aligned}
& \mathrm{k}_{\mathrm{o} 0}=\ln \left(1+\frac{\mathrm{h}_{\mathrm{o}}}{\mathrm{R}}\right) \\
& k_{i 0}=\frac{E_{i}}{E_{o}} \ln \left[\left(1-\frac{h_{c}}{R}\right) /\left(1-\frac{h_{c}}{R}-\frac{h_{i}}{R}\right)\right] \\
& \mathrm{k}_{\mathrm{o} 1}=\frac{\mathrm{h}_{\mathrm{o}}}{\mathrm{R}}-\ln \left(1+\frac{\mathrm{h}_{\mathrm{o}}}{\mathrm{R}}\right) \\
& k_{i 1}=\frac{E_{i}}{E_{0}} \frac{h_{i}}{R}-k_{i 0} \\
& k_{\mathrm{o} 2}=\frac{1}{2}\left(\frac{h_{0}}{\bar{R}}\right)^{2}-\frac{h_{0}}{R}+\ln \left(1+\frac{h_{o}}{R}\right) \\
& k_{i 2}=\frac{-E_{i}}{\bar{E}_{o}}\left[\frac{1}{2}\left(\frac{h_{i}}{R}\right)^{2}+\frac{h_{i}}{R}\left(1+\frac{h_{c}}{R}\right)\right]+k_{i 0} \\
& I_{b 0}=\left(\xi+\xi^{2} / 2\right) \eta \\
& \mathrm{I}_{\mathrm{c} 0}=\left(\xi-\xi^{2} / 2\right) \eta \\
& I_{b 1}=\left(\xi^{2} / 2+\xi^{3} / 3\right) \eta \\
& I_{c 1}=\left(-\xi^{2} / 2+\xi^{3} / 3\right) \eta \\
& \mathrm{I}_{\mathrm{b} 2}=\left(\xi^{3} / 3+\xi^{4} / 4\right) \eta \\
& I_{c 2}=\left(\xi^{3} / 3-\xi^{4} / 4\right) \eta \\
& \xi=\frac{1}{2}\left(\frac{h_{c}}{R-\frac{c}{2}}\right) \\
& \eta=\frac{\rho_{c}}{\rho_{o}}\left(1-\frac{h_{c}}{2 R}\right)^{2} \\
& I_{o 0}=\left(1+.5 h_{o} / R\right) h_{o} / R \\
& I_{i 1}=\left(\psi_{1}+\psi_{2}\right) \rho_{i} / \rho_{\rho} \\
& I_{o I}=\left(.5+h_{o} / 3 R\right) h_{o}^{2} / R^{2} \\
& I_{i 2}=\left(\psi_{2}+\psi_{3}\right) \rho_{i} / \rho_{o} \\
& I_{o 2}=\left(1 / 3+h_{o} / 4 R\right) h_{o}^{3} / R^{3} \\
& \psi_{1}=-.5 \mathrm{~h}_{\mathrm{i}}\left(\mathrm{h}_{\mathrm{i}}+2 \mathrm{~h}_{\mathrm{c}}\right) / \mathrm{R}^{2} \\
& I_{i 0}=\left(h_{i} / R+\psi_{1}\right) \rho_{i} / \rho_{0} \\
& \psi_{2}=\left(\mathrm{h}_{\mathrm{i}}^{3}+3 \mathrm{~h}_{\mathrm{c}} \mathrm{h}_{\mathrm{i}}^{2}+3 \mathrm{~h}_{\mathrm{i}} \mathrm{h}_{\mathrm{c}}^{2}\right) / 3 \mathrm{R}^{3} \\
& \psi_{3}=-\left(h_{i}^{4}+4 h_{c} h_{i}^{3}+6 h_{i}^{2} h_{c}^{2}+4 h_{i} h_{c}^{3}\right) / 4 R^{4}
\end{aligned}
$$

\section{Transient Response Evaluation}

Despite the complexity of Equations (12), they can be used directly for transient response computations without resorting to finite-difference or finite-element approximations. The solution technique is based upon modal series expansions in $\theta$ and a Laplace transform on time. The form of the solution differs from most modal solutions in that no algebraic expressions are derived for the characteristic equation and for modal coefficients. Instead, numerical values for the ring parameters are substituted into an algorithm which computes the ring frequencies, mode shapes, and modal coefficients for the transient response solution. To simplify the solution, the $r$ ing is assumed to be quiescent at $\mathrm{t}=0^{-}$, and only loads even in $\theta$ are considered. Loads odd in $\theta$ and initial velocity or initial deformation problems can be handled with only a slight modification of the procedure outlined below. 
Both the displacement vector and load vector are expanded in Fourier series

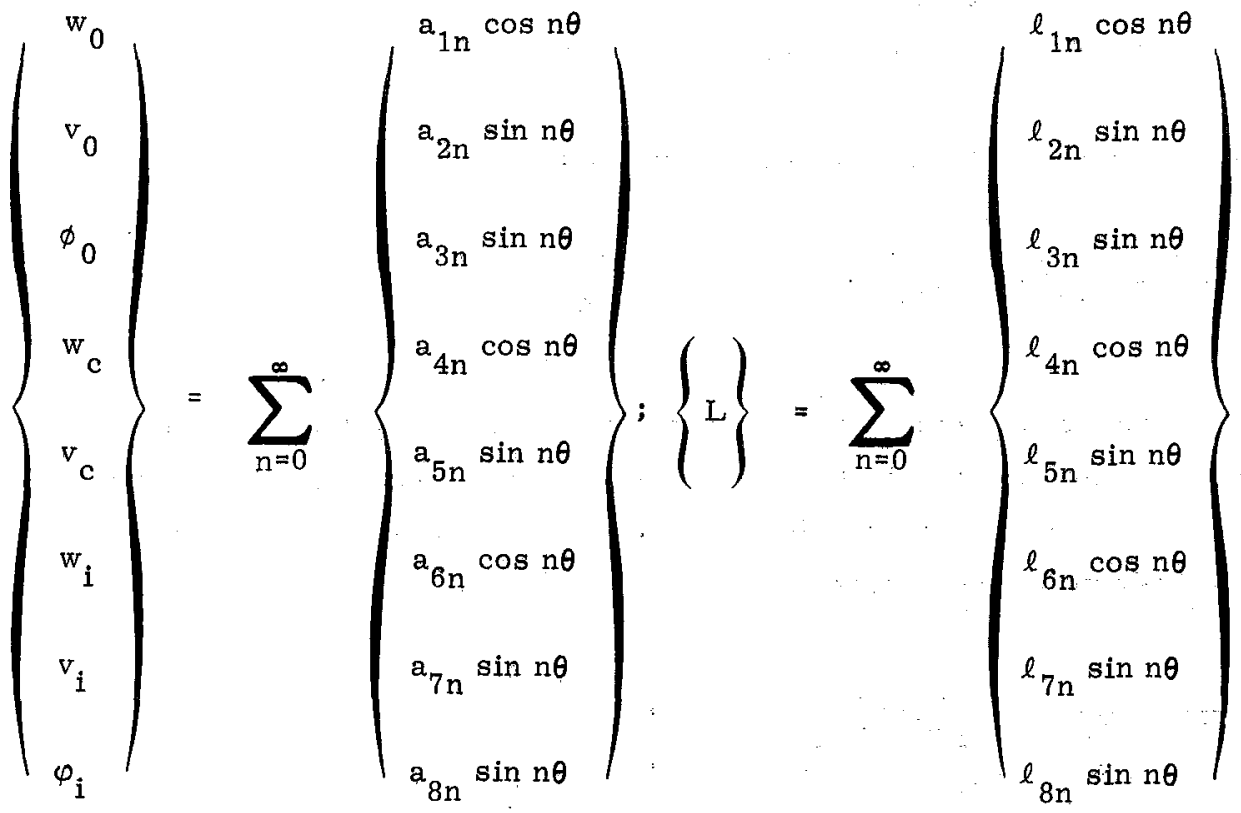

Substituting these series into the equations of motion and taking a Laplace transform on $t$ yields a set of linear algebraic equations with $n$ and the transform variable s as parameters. Orthogonality of the sine and cosine functions uncouples these equations so that they can be solved separately for each $n$. The equations have the form

$$
[\overline{\mathrm{F}}(\mathrm{n}, \mathrm{s})]\left\{\overline{\mathrm{a}}_{\mathrm{n}}\right\}=\left\{\bar{l}_{\mathrm{n}}\right\} \text {, }
$$

where the $(-)$ notation is used to indicate Laplace-transformed quantities. For brevity, the expression for $[\bar{F}(n, s)]$, the coefficient matrix, is not written out here, but this can be very easily done by making the following substitutions in Equations (12): Replace $\frac{\partial^{2}}{\partial \theta^{2}}$ by $-n^{2} ; \frac{\partial^{2}}{\partial t^{2}}$ by $s^{2} ; \frac{\partial}{\partial \theta}$ by $\mathrm{n}$ in columns $2,3,5,7$, and 8 ; and by $-\mathrm{n}$ in columns 1,4 , and 6 . The solution for the Fourier coefficients can be written formally as

$$
\left\{\overline{\mathrm{a}}_{\mathrm{n}}\right\}=[\overline{\mathrm{F}}]^{-1}\left\{\bar{\ell}_{\mathrm{n}}\right\}=\frac{[\overline{\mathrm{M}}]}{\mathrm{D}}\left\{\bar{\ell}_{\mathrm{n}}\right\}
$$

or, using indicial notation but not the summation convention,

$$
\bar{a}_{\text {in }}=\sum_{j=1}^{8} \frac{\overline{\mathrm{M}}_{i j n}\left(s^{2}\right)}{D_{n}\left(s^{2}\right)} \bar{\ell}_{j n}(s)
$$

Here $\overline{\mathrm{M}}_{i j n}$ and $\overline{\mathrm{D}}_{\mathrm{n}}$ are the cofactor matrix and determinant of the transformed equations for a given n. 
Obtaining algebraic expressions for $\overline{\mathrm{M}}_{i j n}$ and $\overline{\mathrm{D}}_{\mathrm{n}}$ would be prohibitively difficult, but this is no impediment to their use in the solution. They are simply carried along and used formally during the analysis. When numerical solutions are required, these quantities need only be evaluated for specific numerical values of $n$ and $s^{2}$ via a suitable algorithm.

Symbolically the determinant can be expressed in product form

$$
\overline{\mathrm{D}}_{\mathrm{n}}=\mathrm{A}\left(\mathrm{s}^{2}+\omega_{1 \mathrm{n}}^{2}\right)\left(\mathrm{s}^{2}+\omega_{2 \mathrm{n}}^{2}\right) \cdots \cdots\left(\mathrm{s}^{2}+\omega_{8 \mathrm{n}}^{2}\right)=\mathrm{A} \prod_{\mathrm{k}=1}^{8}\left(\mathrm{~s}^{2}+\omega_{\mathrm{kn}}^{2}\right)
$$

where $A$ is a constant and the $\omega_{\mathrm{kn}}$ 's are the natural frequencies of the system for a given $\mathrm{n}$. For a specific set of ring parameters, numerical values for the $\omega_{\mathrm{kn}}$ 's can be computed as described in Appendix A. Then, for each $n$, the known values for the $\omega_{k n}$ 's are used to write partial fraction expansions for the transformed coefficients,

$$
\bar{a}_{i n}=\sum_{k=1}^{8}\left\{\sum_{j=1}^{8} \frac{M_{i j n}\left(-\omega_{k n}^{2}\right)}{\substack{A \neq k \\ l \neq k}_{\left(\omega_{\ell n}^{2}-\omega_{k n}^{2}\right)} \bar{\ell}_{j n}(s)}\right\} \frac{1}{s^{2}+\omega_{k n}^{2}}
$$

With the values of the $\omega_{\mathrm{kn}}{ }^{\prime} \mathrm{s}$ known, the numerical values for the minors, $\mathrm{M}_{\mathrm{ijn}}\left(-\omega_{\mathrm{kn}}^{2}\right)$, are easily calculated. The Laplace inversion of Equation (18) can be written in terms of convolution integrals by using the formula,

$$
\mathscr{L}^{-1} \frac{\ell_{\mathrm{jn}}(\mathrm{s})}{\mathrm{s}^{2}+\omega_{\mathrm{kn}}^{2}}=\int_{0}^{\mathrm{t}} \ell_{\mathrm{jn}}(\tau) \sin \omega_{\mathrm{kn}}(\mathrm{t}-\tau) / \omega_{\mathrm{kn}} \mathrm{d} \tau
$$

The result is

$$
a_{i n}(t)=\sum_{k=1}^{8} \sum_{j=1}^{8} \frac{M_{i j n}\left(-\omega_{k n}^{2}\right)}{\substack{A \\ \ell \neq k}\left(\omega_{\ell n}^{2}-\omega_{k n}^{2}\right)} \int_{0}^{t} \ell_{j n}(\tau) \sin \omega_{k n}(t-\tau) / \omega_{k n} d \tau .
$$

Formally the solution is completed by substituting this expression for the Fourier coefficients into the series expansions for displacements. To obtain strains, the se displacement expansions are in turn substituted into the strain-displacement relations.

Equation (20) shows that, for each $n$, eight different modes of vibration can contribute to each displacement, but usually only a few (three or four) of the modes will make a significant contribution. The relative importance of the modes depends on the applied load, the displacement or strain component of interest, and the physical parameters of the ring. Because of the wide range of parameters for which this theory is applicable, it is best to treat each case individually. For 
example, when $\mathrm{n}=0$, the lowest frequency is 0 because it represents a rigid body motion. The lowest nonzero frequency can represent either a purely radial or purely circumferential (thickness shear) motion depending on the ring parameters.

The brief presentation of the analysis given here helps to avoid overloading the discussion with details. However, this approach provides little insight into the origin and possibly physical interpretation of the terms in Equation (20). An attempt to provide some interpretation of the solution is presented in Appendix B.

\section{Solution for Cosine-Distributed Impulse}

As an example, the equations of motion and solution technique are used to calculate the transient response of a three-layered ring to a radial impulse. The impulse is applied to the outer ring surface and is distributed as a cosine over half the ring circumference, i. e.

$$
\begin{aligned}
& \ell_{1}= \begin{cases}\frac{I}{E_{0}}\left(R+h_{0}\right) \delta(t) \cos \theta & |\theta|<\pi / 2\end{cases} \\
& 0 \quad|\theta|>\pi / 2 \\
& \ell_{j}=0 \quad j \neq 1
\end{aligned}
$$

Expanding the load in a Fourier series gives

$$
\begin{aligned}
& \ell_{1}=\frac{I}{E_{0}}\left(R+h_{0}\right) \delta(t)\left[\frac{1}{\pi}+\frac{\cos \theta}{2}-\sum_{n=2,4,6}^{\infty} \frac{(-1)^{n / 2} 2}{\pi\left(n^{2}-1\right)} \cos n \theta\right] \\
& \ell_{1}=\frac{I}{E_{0}}\left(R+h_{0}\right) \delta(t) \sum_{n=0}^{\infty} \ell_{1 n} \cos n \theta .
\end{aligned}
$$

This particular load leads to a relatively simple form for the Fourier coefficients because only one element in the load vector is nonzero and the $\delta(t)$ behavior simplifies evaluation of the convolution integrals. The Fourier coefficients are

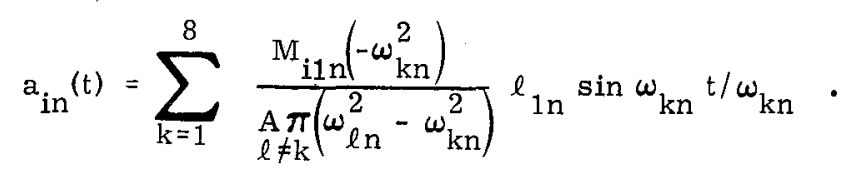

A computer program was written to evaluate these Fourier coefficients, sum the series expansions, and provide a prediction for strain-time. 


\section{Experiment}

Ring Specimens

To obtain strain-time transient response data for comparison with theoretical predictions, three different three-layered rings were assembled. Each ring had a relatively thick, soft core layer because the theory was especially formulated to handle this case. Inner and outer layers of all the specimens were 1/8-inch-thick 6061-T6 aluminum and the outside diameter was 12.5 inches for each case. The core layers were (1) 0.5 inch thick, $12 \mathrm{lb} / \mathrm{ft}^{3}$, CPR 2038 urethane foam (Ref. 12, 13); (2) 0.25 inch thick, $20 \mathrm{lb} / \mathrm{ft}^{3}$, CPR 2038 urethane foam; and (3) 0.25 inch thick Sylgard $(R)$ 184. The resiliant urethane foam cores were cut from a flat sheet and glued to the aluminum layers with contact adhesive. Sylgard 184 is a low-modulus, clear potting compound manufactured by the Dow Corning Company. The Sylgard core was poured in place.

\section{Impulse Loading Techniques}

Two radial impulse load distributions were applied to the outer surface of each ring, axisymmetric and varying as $\cos \theta$ for $-\pi / 2<\theta<\pi / 2$. Figure $3 \mathrm{a}$ is a schematic of the loading setup for the axisymmetric impulse case (Reference 14). The ring is first wrapped with a layer of insulating Mylar. A 2-inch-wide strip of thin aluminum is wrapped on and its ends shorted together. Another insulation layer is added; another wrap of aluminum follows, with its ends connected to the capacitor bank terminals. At switch closure, bank discharge current flows in the outer conductor and induces an opposing current in the inner conductor. Repulsion between the two current-carrying conductors blows away the outer conductor and drives the other radially inward against the sample ring, thus applying uniform radial impulse. The junction that shorts the inner conductor is formed to permit outward radial rebound of the ring under minimum restraint by the aluminum layer.

The loading technique used to obtain a cosine impulse over half the circumference is shown in Figure 3b (Reference 15). A single conductor, insulated and folded back on itself, carries the bank discharge current. The outer part of the conductor is blown away and the inner part is driven against the sample ring which is allowed to fly freely upward. Conductor width is varied as the appropriate function of angle $\theta$ in order to produce the required spatial load profile (Reference 16).

The pressure time history for both types of load distributions is governed by the parameters of the electrical circuit. For these tests the load was delivered in less than $10 \mu$ sec with most of the impulse delivered within the first $4 \mu$ sec. This load duration is short enough to be considered impulsive. 

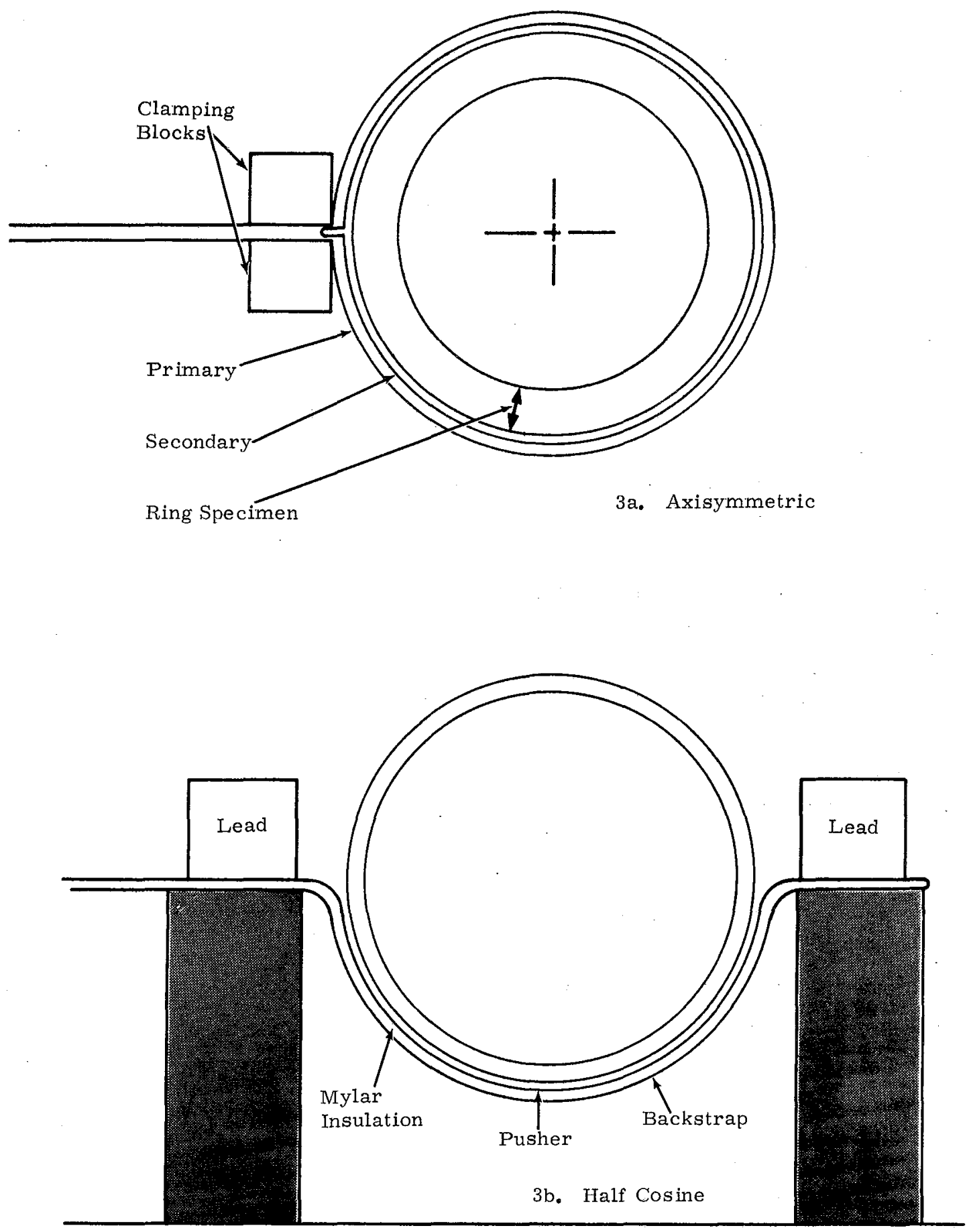

Figure 3. Experimental Setups 
Instrumentation

Strain gages were used to monitor the transient ring response. For the cosine impulse loads, the gages were located on the inner ring surface at $\theta=0, \pi / 2$, and $\pi$. Additional gages at $\pi$ were located on the aluminum layers at their interfaces with the core and on the outside surface of the outer layer. The gage locations were the same for axisymmetric loads except that no gage was used on the outer surface. Strain data were recorded on magnetic tape, digitized, and plotted. A camera and multiflash light source were used to obtain time-lapse photographs of the ring for the cosine impulse loads. From these pictures, rigid body velocity and net impulse delivered to the ring were determined.

\section{Core Material Properties}

Modulus properties for the urethane foams were obtained by extrapolating from data published in References 12 and 13. Since these foams have strain-rate-sensitive moduli, the extrapolations were made from the highest strain-rate information given. No modulus data were available for Sylgard 184, but some simple static tests, along with ultrasonic wave transit time measurements, were used to estimate material properties. The ultrasonic tests showed a wave transit time through a $1 / 4$-inch-thick Sylgard core of $5.8 \mu$ sec. This is an order of magnitude less than the transit time that would have been anticipated based on the modulus obtained from a simple tension test of a Sylgard bar. Apparently the confinement of the Sylgard core between aluminum layers effectively stiffens the material due to a relatively high bulk modulus. Values that correlated with the ultrasonic wave speed data were chosen for the $c_{1}, c_{2}$, and $c_{3}$ core moduli (see Equation 2). Since confinement has no effect on shear stiffness, the value chosen for the shear modulus, $c_{4}$, was close to the statically determined value.

Comparison of Predictions with Measurements

The core materials used in the ring specimens contribute substantial damping to the system. Since the theory was formulated for elastic materials, some sort of loss factor must be introduced into the calculations to have any hope of achieving good experimental-theoretical correlation at other than very early times. This was accomplished by multiplying the contribution of each mode by a damping function, $\exp (-\delta \mathrm{t} / \mathrm{T})$, where $\delta$ is a logarithmic decrement and $\mathrm{T}$ is the period of the mode. Satisfactory convergence for the cosine impulse load was obtained by truncating all series expressions for the transient ring response at $n=12$. Since there are eight modes of vibration for each $n$, there are many log decrements to be specified. To simplify this situation, the log decrement for the lowest frequency mode was assumed to be the same for all $\mathrm{n}$. Similarly, this assumption was extended to each of the other seven modes so only eight log decrements need be specified. Two of these eight quantities were obtained experimentally. One was determined by using the technique described in Reference 14 in conjunction with the axisymmetric impulse tests. The other was found by observing the long-time strain response from the half-cosine impulse tests. In this case 
the high-frequency modes damp quickly, and only the fundamental bending mode vibration remains at late times (see Figure 4). Thus the log decrement for the fundamental bending mode was easily found from the late-time strain data. With the two experimentally determined values for log decrement as guides, values for the remaining six modes were chosen. It should be noted that the modes for which the log decrements were determined experimentally are responsible for a large part of the total transient response.

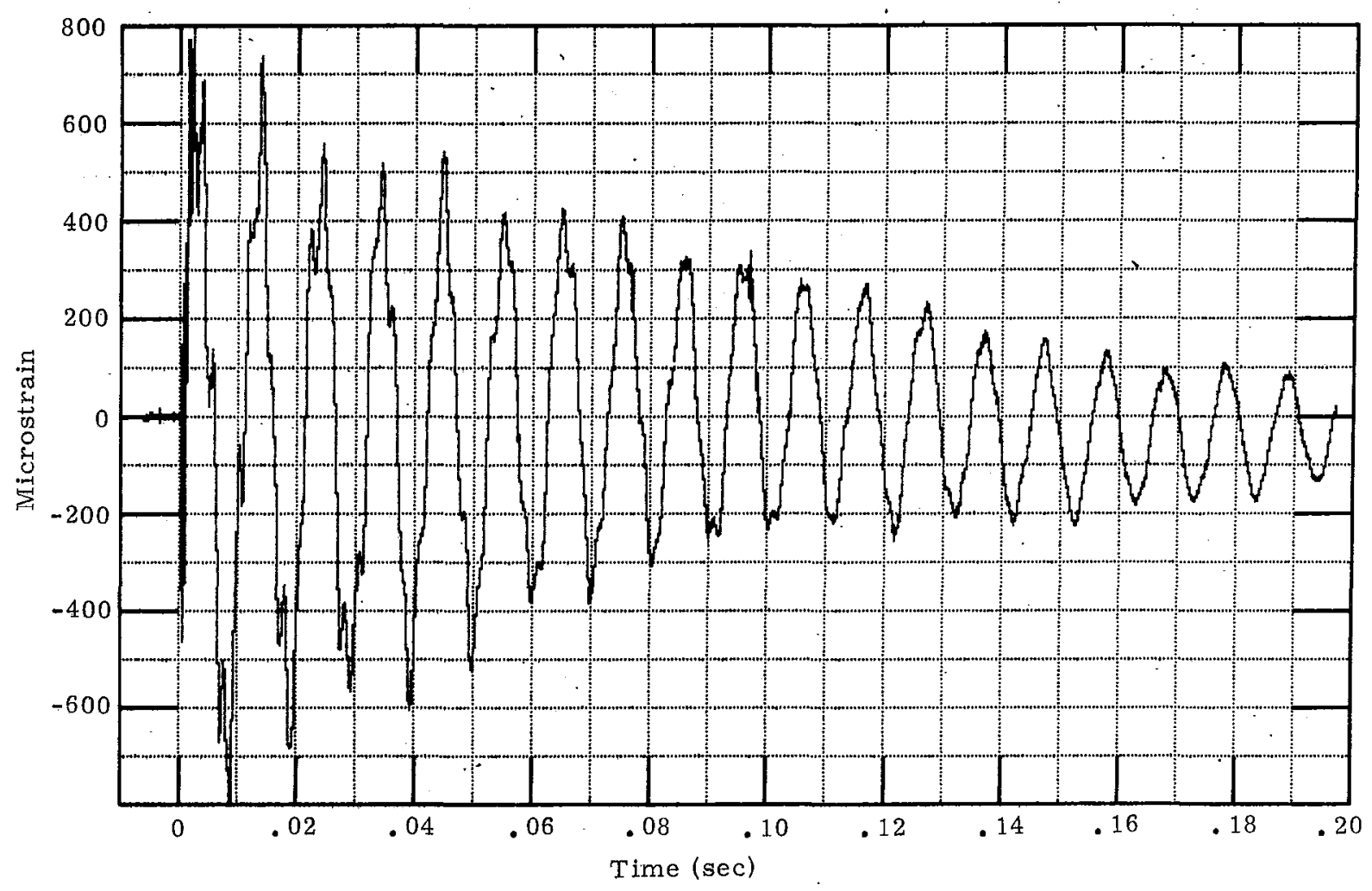

Figure 4. Long Time Strain Response

Each of the rings was loaded twice with the cosine impulse. Both experiments were performed at about the same impulse magnitude and, for comparison purposes, the results were scaled to a common reference impulse level. The scaled results along with theoretical predictions are shown in Figures 5 through 7 for the ring with $12-1 b / \mathrm{ft}^{3}$ urethane foam, Figures 8 through 10 for the ring with $20-\mathrm{lb} / \mathrm{ft}^{3}$ urethane foam, and Figures 11 through 13 for the ring with a Sylgard 184 core. The material parameters used in the calculations for each of the rings are shown in Table $I_{\text {. The }} \delta_{1}$ notation is used for the log decrement of the lowest frequency mode, $\delta_{2}$ is the log decrement for the second lowest frequency mode, etc. 

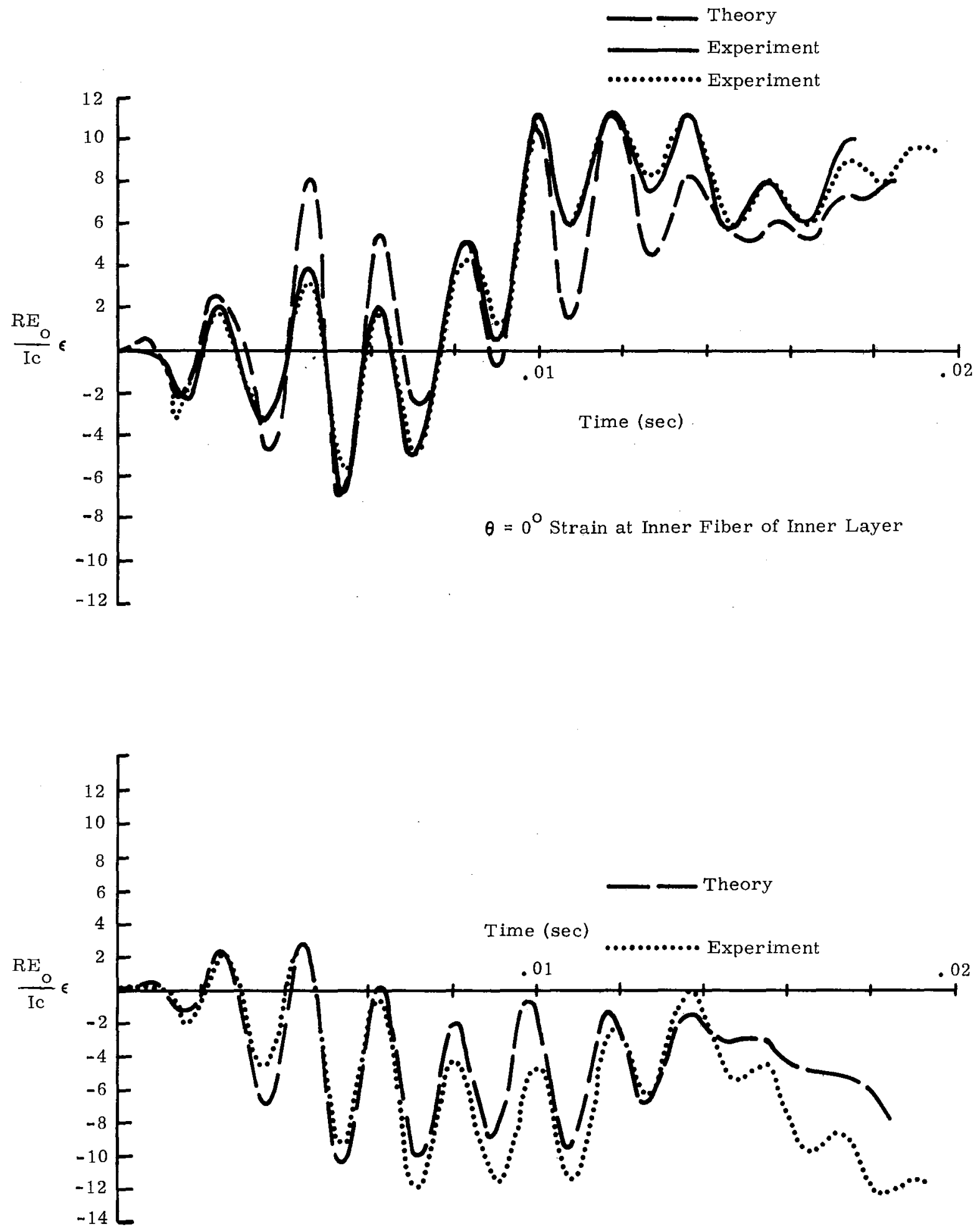

$\theta=90^{\circ}$ Strain at Inner Fiber of Inner Layer

Figure 5. Strain vs Time for Ring with $12 \mathrm{Lb} / \mathrm{Ft}^{3}$ Foam Core 

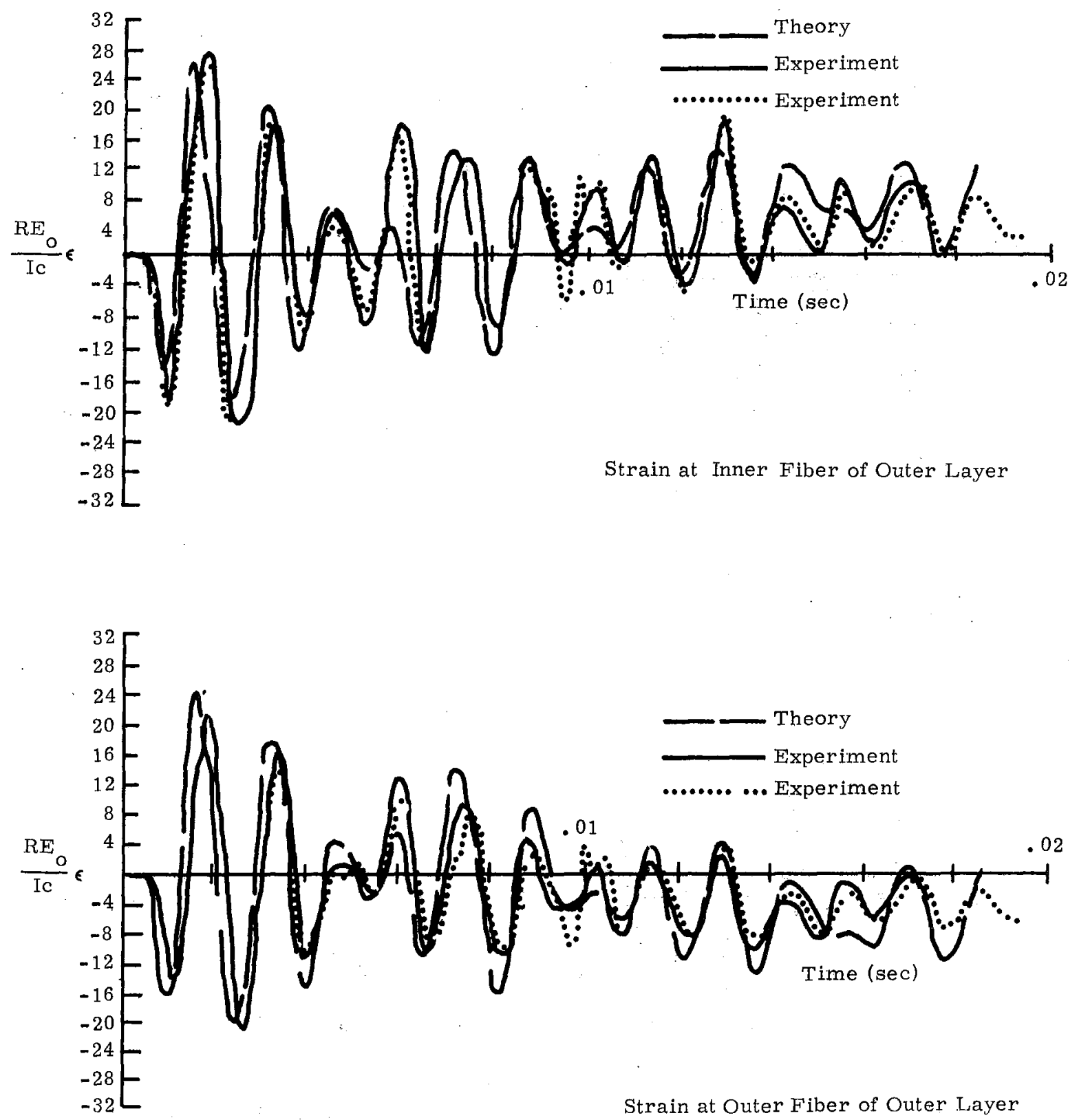

Figure 6. Strain vs Time at $\theta=180^{\circ}$ for Ring with $12 \mathrm{Lb} / \mathrm{Ft}^{3}$ Foam Core 

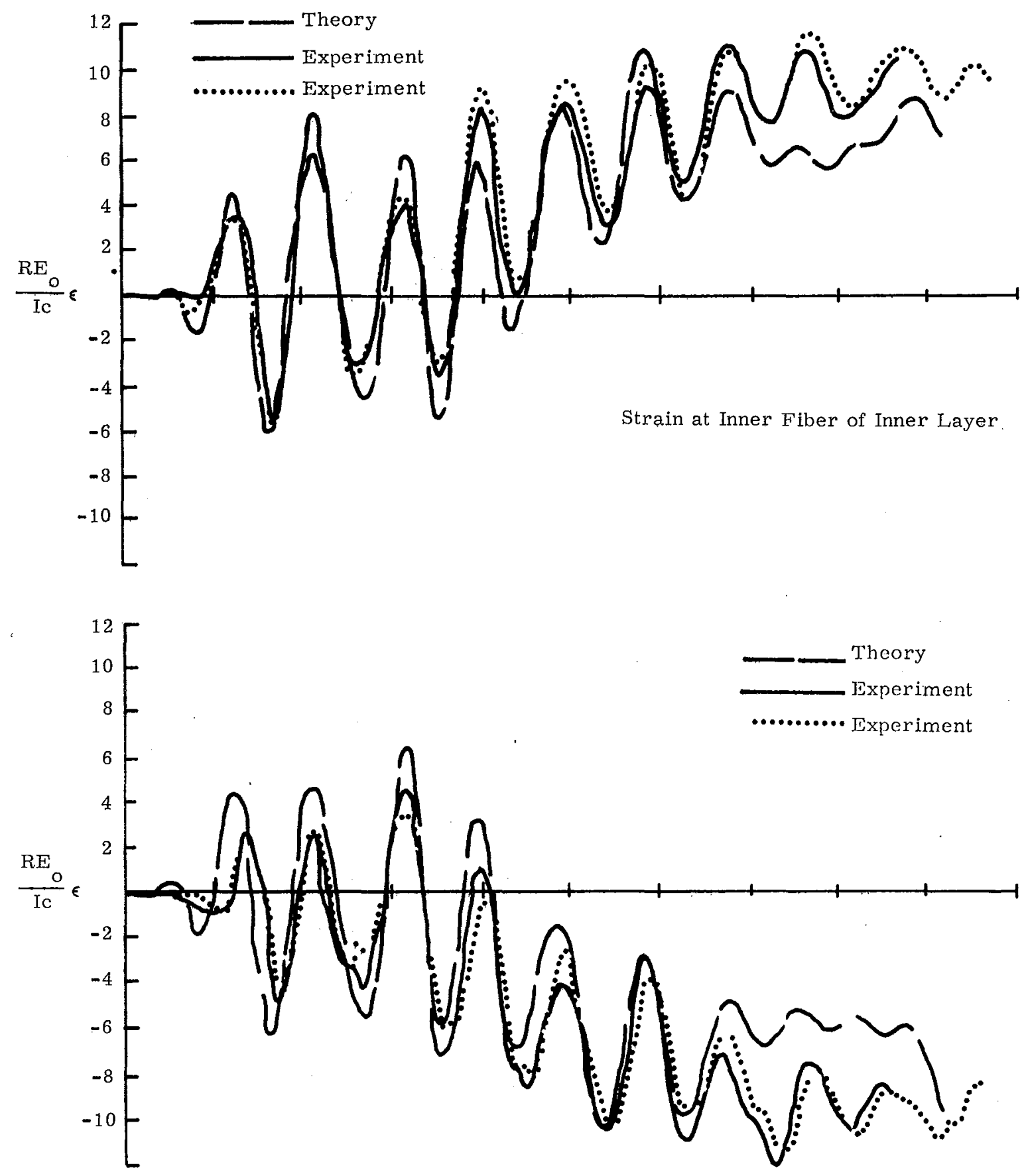

Strain at Outer Fiber of Inner Layer

Figure 7. Strain vs Time at $\theta=180^{\circ}$ for Ring with $12 \mathrm{Lb} / \mathrm{Ft}^{3}$ Foam Core 

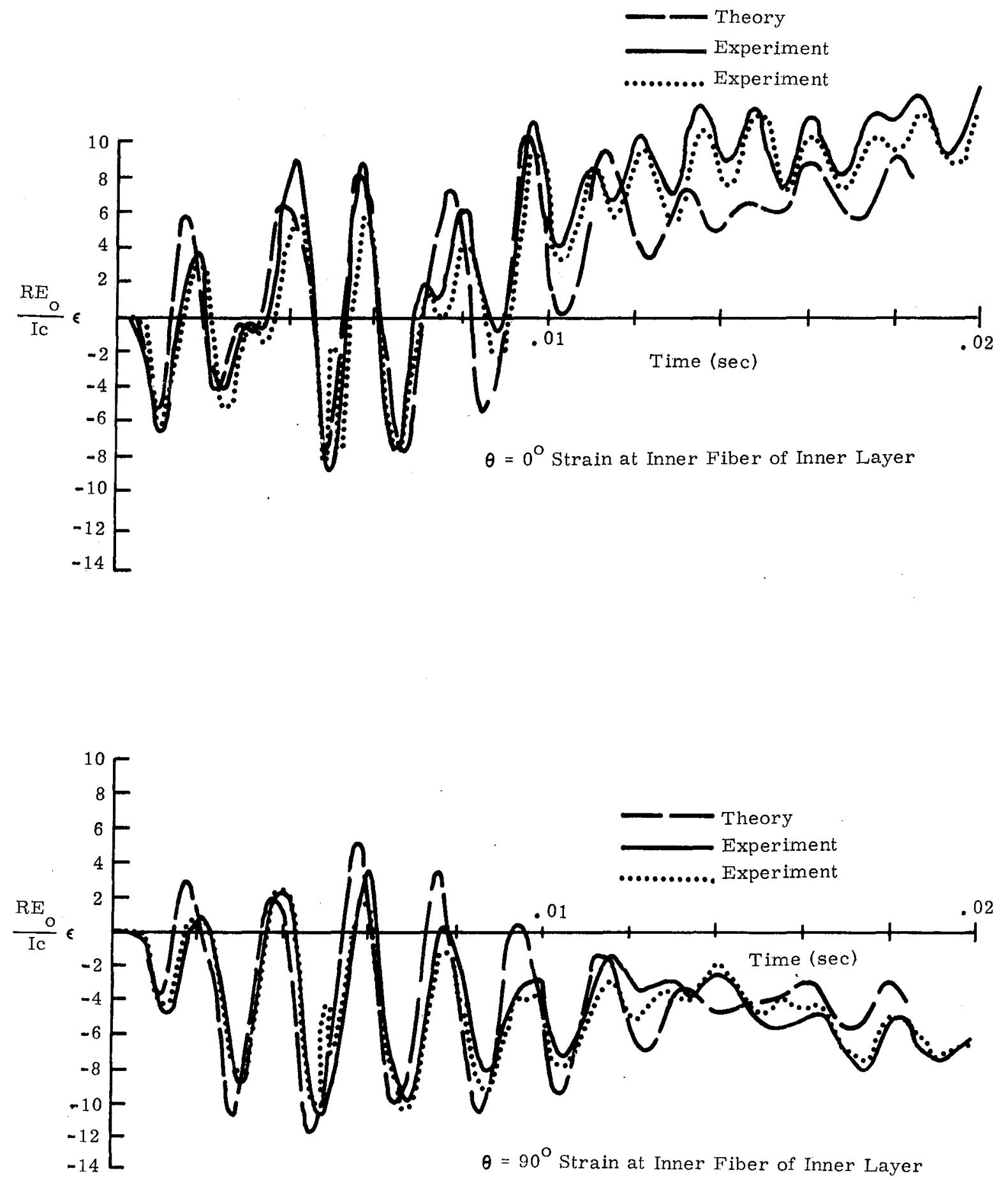

Figure 8. Strain vs Time for Ring with $20 \mathrm{Lb} / \mathrm{Ft}^{3}$ Foam Core 

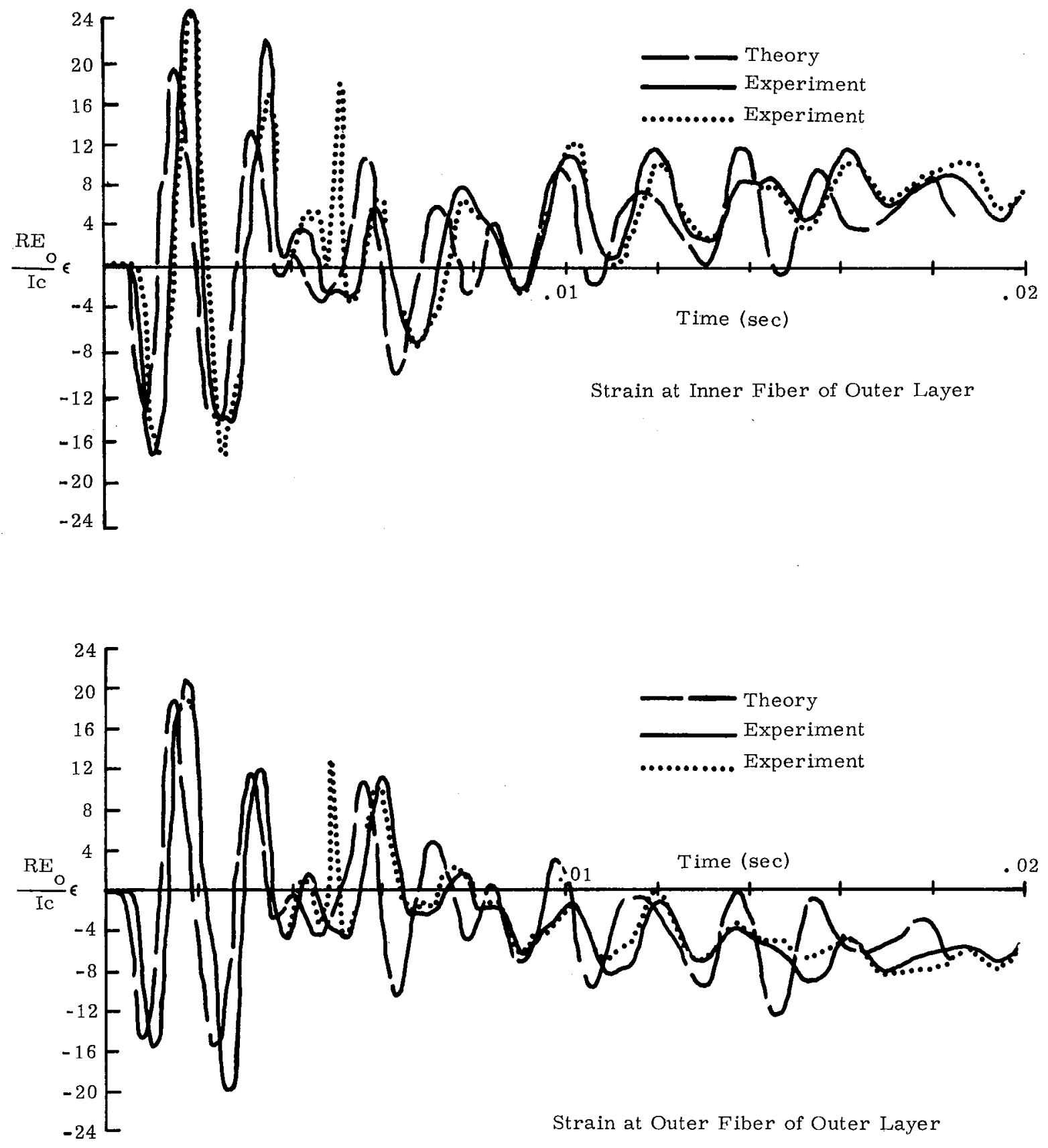

Figure 9. Strain vs Time at $\theta=180^{\circ}$ for Ring with $20 \mathrm{Lb} / \mathrm{Ft}^{3}$ Core 

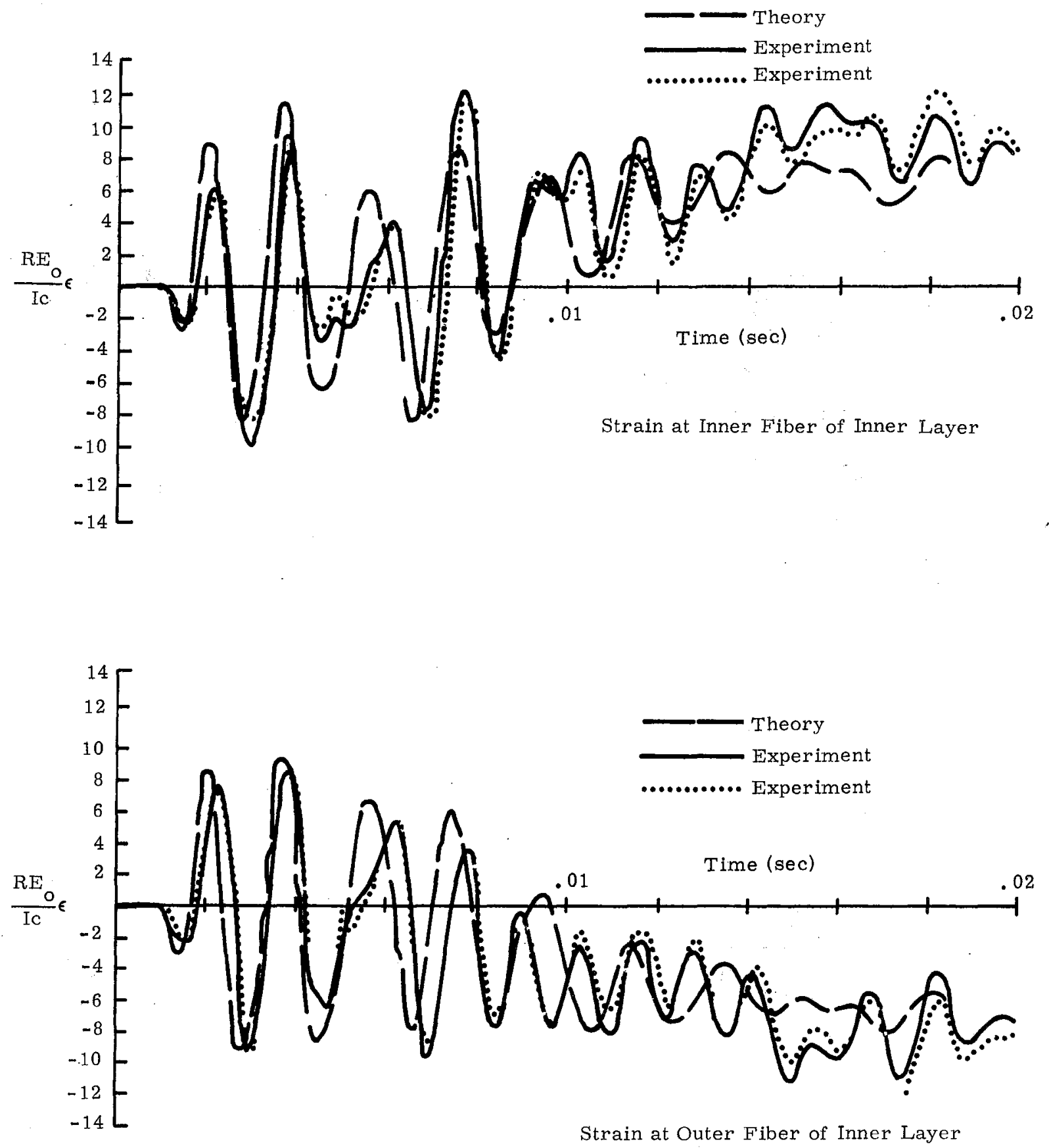

Figure 10. Strain vs Time at $\theta=180^{\circ}$ for Ring with $20 \mathrm{Lb} / \mathrm{Ft}^{3}$ Foam Core 

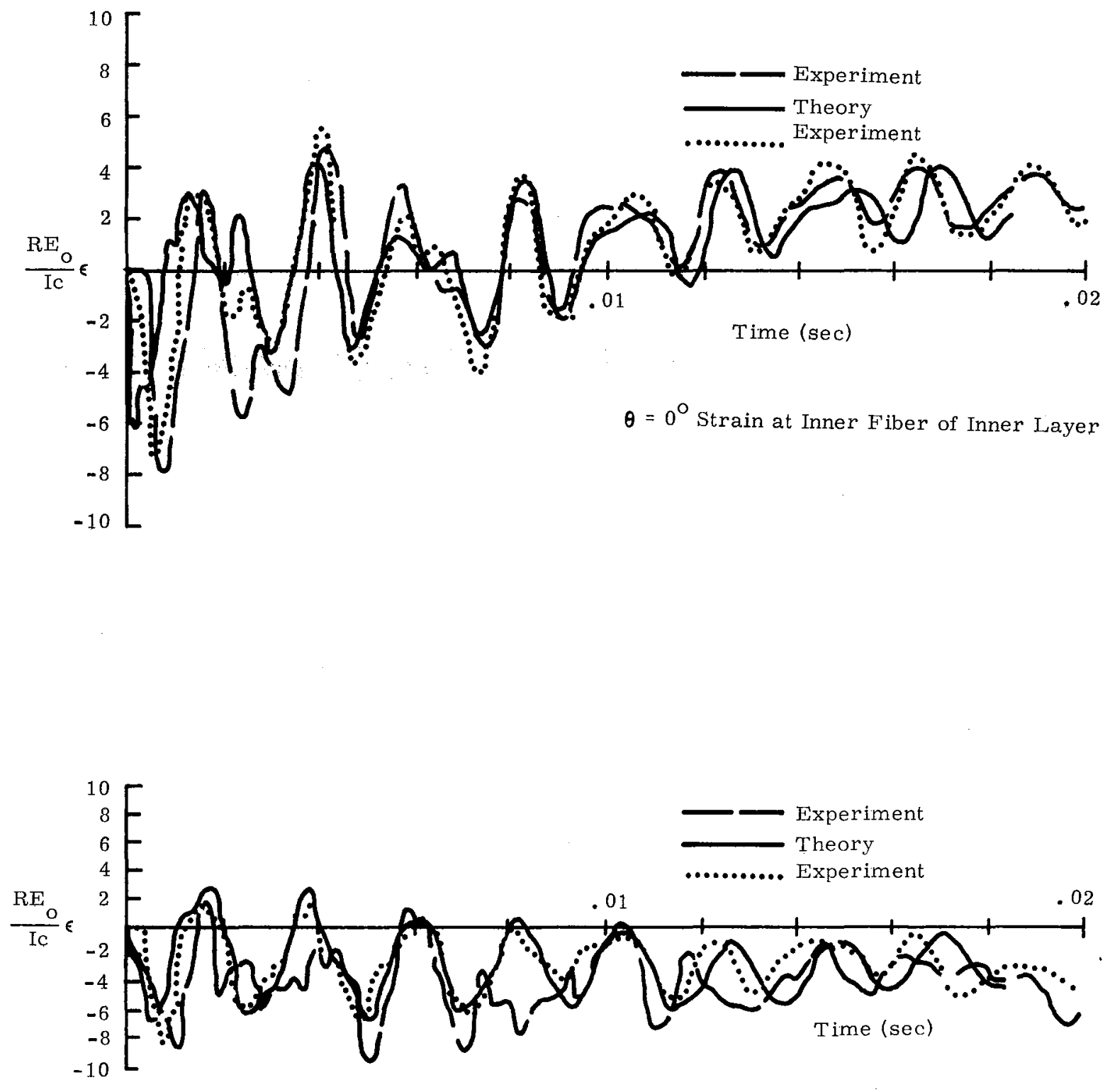

$\boldsymbol{\theta}=90^{\circ}$ Strain at Inner Fiber of Inner Layer

Figure 11. Strain vs Time for Ring with Sylgard Core 

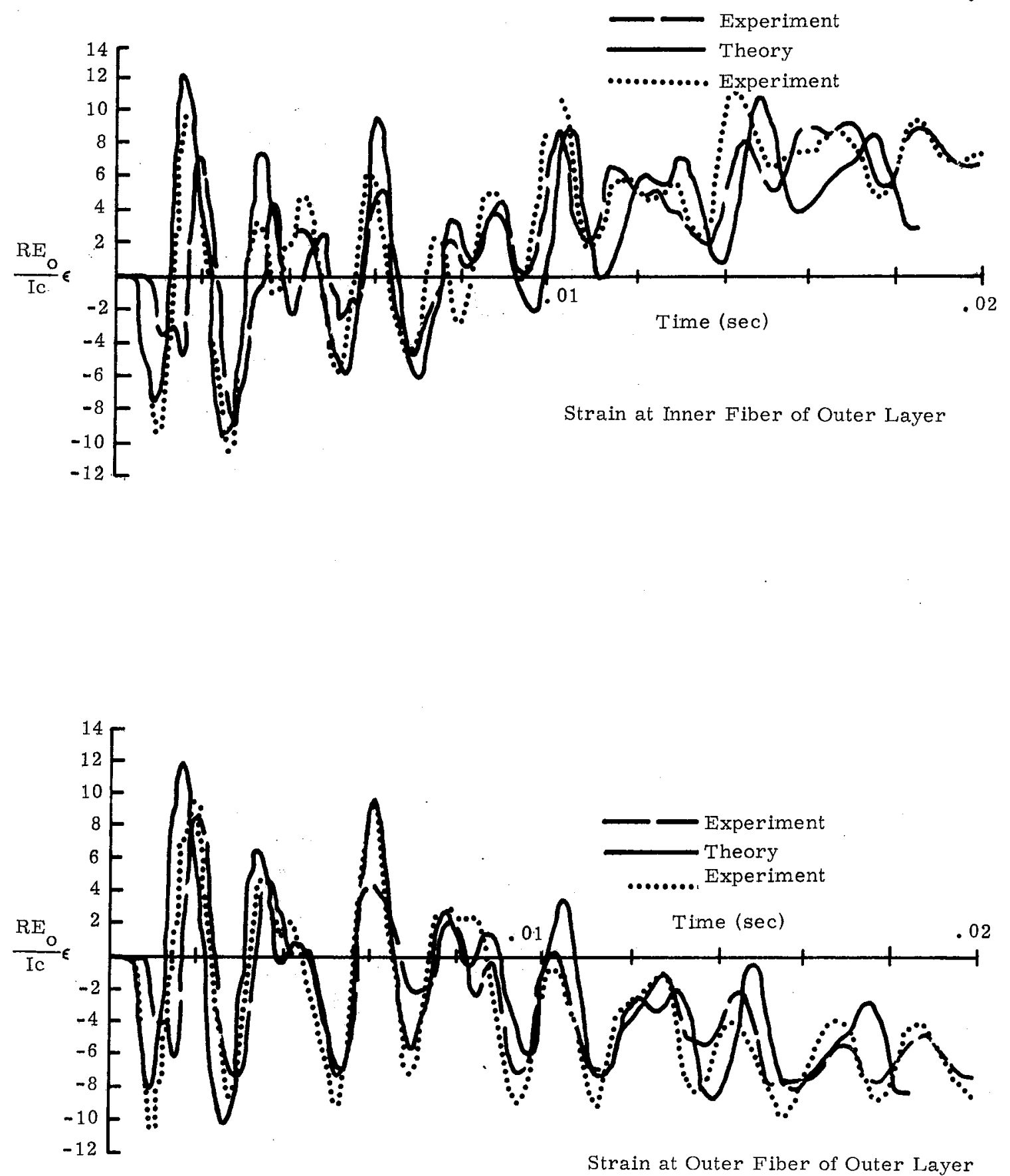

Figure 12. Strain vs Time at $\theta=180^{\circ}$ for the Ring with Sylgard Core 

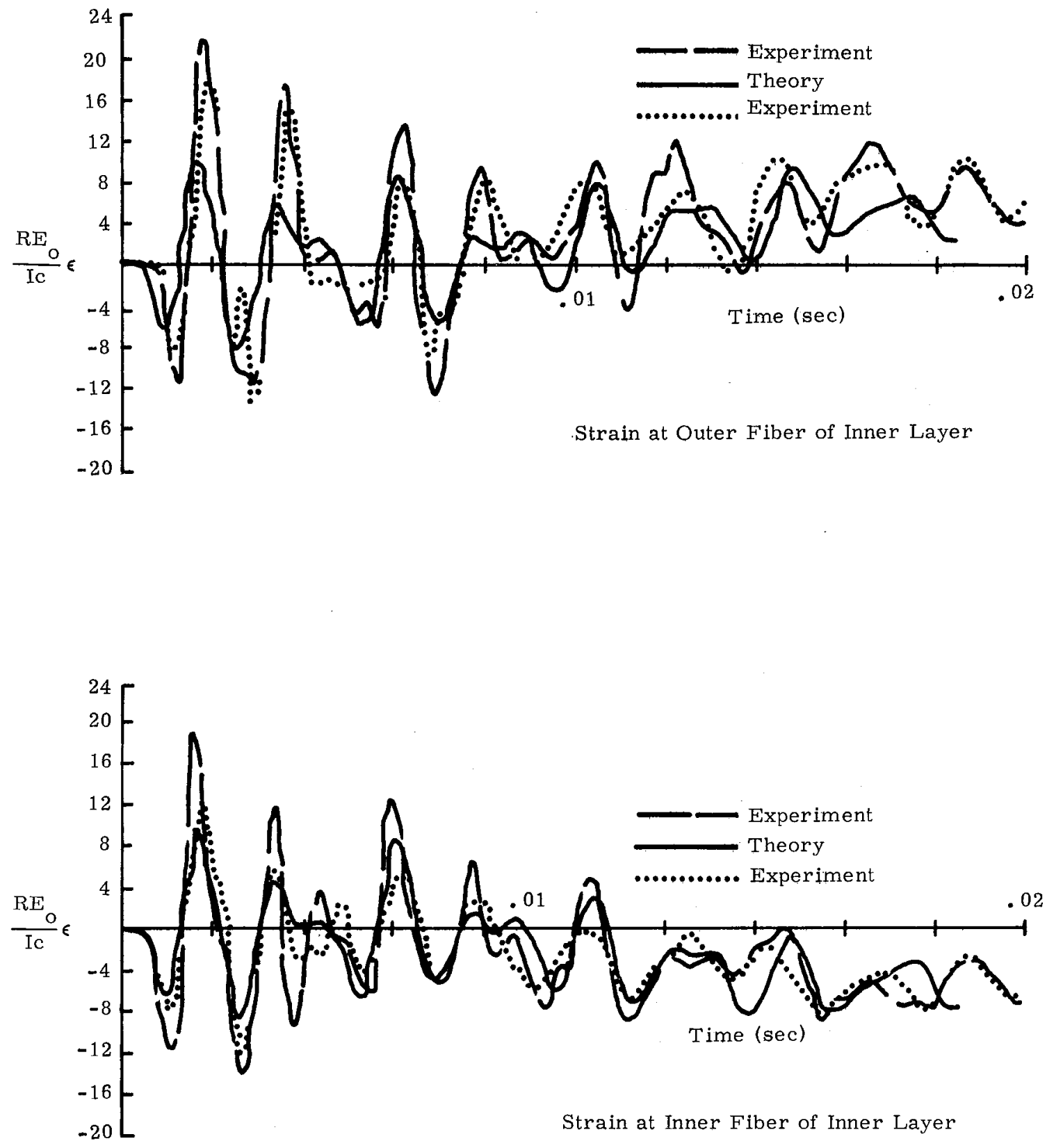

Figure 13. Strain vs Time at $\theta=180^{\circ}$ for Ring with Sylgard Core 
TABLE I

Material Properties

$$
\frac{E_{0}(\mathrm{~Pa})}{6.9 \times 10^{10}} \frac{\mathrm{E}_{\mathrm{i}}(\mathrm{Pa})}{6.9 \times 10^{10}} \quad \frac{\mathrm{G}_{\mathrm{o}}(\mathrm{Pa})}{2.9 \times 10^{10}} \quad \frac{\mathrm{G}_{\mathrm{i}}(\mathrm{Pa})}{2.9 \times 10^{10}} \quad \frac{\rho_{\mathrm{o}}\left(\mathrm{g} / \mathrm{mm}^{3}\right)}{2.7 \times 10^{-3}} \cdot \frac{\rho_{i}\left(\mathrm{~g} / \mathrm{mm}^{3}\right)}{2.7 \times 10^{-3}}
$$

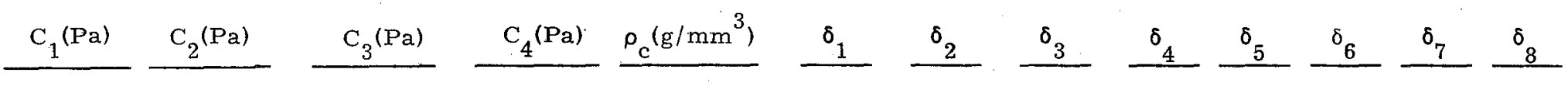

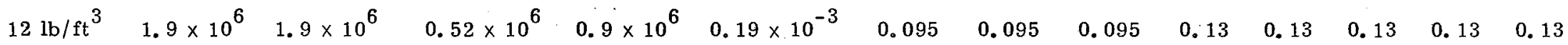

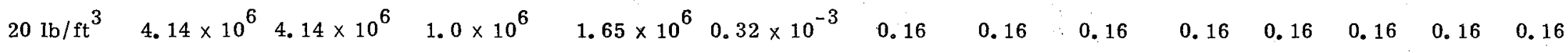

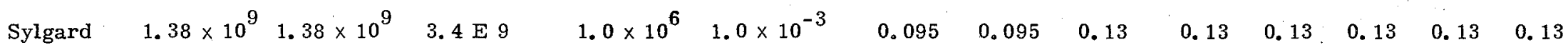


The theoretical-experimental correlation shown in Figures 5 through 10 for the foam core rings is quite good, but this agreement is partly due to adjusting core material properties used in the calculations. The modulus properties chosen are all well within a reasonable range based upon the limited data available, but the limited amount of data resulted in a fairly wide range of reasonable values. The logarithmic decrements were based upon some limited experimental data and several assumptions. If no experimental data were available for the rings, approximate values for log decrements could have been computed from specific loss (Reference 17) properties of the core materials. This is done by computing the ring frequencies and mode shapes and then calculating the fraction of the strain energy for each mode due to shear and direct strains in the core. The log decrement is then determined using this fraction and the specific loss factor for the core material.

Theoretical-experimental correlation for the Sylgard ring was not as close as for the foam core rings. The short-duration load produced some high-frequency, high-strain rate pulses directly underneath the load. The transit time of these pulses through the Sylgard core was so short that relief waves propagating inward from the edges of the ring could have little effect. Therefore, at early times, the Sylgard core behaved as if it were completely confined (i. e. , in plane strain). At later times (greater than $50 \mu \mathrm{sec}$ ) the transient ring response is dominated by oscillations whose periods are sufficiently long that the relief waves from the ring edges can have a significant effect. In this case the appropriate core stiffness parameters are dramatically reduced and approach those appropriate for an unconfined or plane stress condition. The large-value stiffness parameters used for the Sylgard computations give reasonably good agreement with the experimental data but tend to underestimate the strains at $\theta=180^{\circ}$.

A further complication in the Sylgard ring analysis arises from the fact that Sylgard does not bond well to many materials and specifically to aluminum. The extent of core debonding is undoubtedly not constant from experiment to experiment and probably is the major factor in the differences in the data presented in Figures 11, 12, and 13. Despite these difficulties, the Sylgard ring data are included in this report for two reasons. First, to point out some pitfalls to be avoided in any future experimental studies, and second, to show that, in some cases, strain time response is sufficiently insensitive to core material parameters that reasonable results can be obtained, even though the core properties are not well known or are effectively changing with time.

For the rings used in this study, it was found that the numerical results are insensitive to the core extensional stiffness in the circumferential direction. This is the result of the very high stiffness of the aluminum layers in comparison with the core. The radial core stiffness is very important since it determines the extent of the coupling between the radial motion of the aluminum layers. The shear parameter $\mathrm{c}_{4}$ (see Equation 2) has an important effect on the lowest frequency bending-type modes since it determines the degree of coupling between the flexural behavior of the aluminum layers. It was observed that inclusion of the core inertia had little effect on the overall ring inertia, frequencies, and peak strains (especially for the light foam cores). However, without core inertia, the theory could not represent the delay time between application of the impulse and initial strain in the inner ring. This delay time corresponds to a wave transit time through the core, and, in the case of the $12-\mathrm{lb} / \mathrm{ft}^{3}$ urethane foam core, amounts to almost $100 \mu \mathrm{sec}$ or about half a period of the dominant axisymmetric extensional vibration. 
1. J. P. Jones and J. S. Whittier, "Dynamics of a Flexibly Bonded Two-Layered TimoshenkoType Cylindrical Shell, " AIAA Journal, Vol. 7, No. 2, February 1969, pp. 244-250.

2. R. DiTaranto, "Free and Forced Response of a Laminated Ring, " Jnl. of the Acoustical Society of America, Vol. 53, No. 3, 1973, pp. 748-757.

3. H. N. Chu, "Vibrations of Honeycomb Sandwich Cylinders," Inl. of the Aerospace Sciences, Vol. 28, December 1961, pp. 930-944.

4. S. Srinivas, Analysis of Laminated, Composite, Circular Cylindrical Shells with General Boundary Conditions, NASA-TR-R-412, NASA, Washington, D. C. , Apri1 1974.

5. C. T. Sun and J. M. Whitney, "Axisymmetric Vibrations of Laminated Composite Cylindrical Shells," Jnl. of the Acoustical Society of America, Vol. 55, No. 6, June 1974, pp. 12381246.

6. P. Underwood, et al., "Transient Response of Soft Bonded Multilayered Shells, " AIAA Journal, Vol. 13, No. 3, March 1975, pp. 350-356.

7. M. J. Sagartz and M. J. Forrestal, "Membrane Response of a Two-Layered, Circular Shell Including the Effects of an Interlayer Bond, " AIAA Journal, Vol. 6, No. 9, September 1968, pp. $1816-1818$.

8. J. J. Ruminer and I. K. McIvar, "Dynamic Response of an Elastic Cylindrical Shell-Solid Core Composite Subject to Time-Dependent Loading, " AIAA Journal, Vol. 9, No. 10, October 1971, pp. 1991-1996.

9. W. E. Alzheimer, M. J. Forrestal, and W. B. Murfin, "Transient Response of Cylindrical, Shell-Core Systems," AIAA Journal, Vol. 6, No. 10, October 1968, pp. 1861-1866.

10. M. J. Forrestal, W. E. Alzheimer, and D. B. Longcope, "Transient Response of a Cylindrical Shell Containing an Orthotropic Core," AIAA Journal, Vol. 8, No. 9, September 1970, pp. 1638-1643.

11. M. J. Sagartz, "Response of a Three-Layered Ring to an Axisymmetric Impulse, "AIAA Journal, Vol. 12, No. 3, March 1974, pp. 390-392.

12. P. B. Rand, Intermediate Strain-Rate Compression Properties of a Filled Flexible Polyurethane Foam at Four Density Levels, SC-DR-68-27, Sandia Laboratories, Albuquerque, NM, February 1968.

13. P. B. Rand, Environmental Resistance and Engineering Properties of Flexible Polyurethane Foams, SC-TM-67-821, Sandia Laboratories, Albuquerque, NM, December 1967.

14. M. J. Forrestal and M. J. Sagartz, "Transient Vibration Experiments for Determination of Properties for Viscoelastic Structures, " Journal of Applied Mechanics, Vol. 42, No. 1, 1975, pp. 205-208.

15. M. J. Forrestal and D. K. Overmier, "An Experiment on an Impulse Loaded Ring, "AIAA Journal, Vol. 12, No. 5, May 1974, pp. 722-724.

16. R. Bealing, Impulse Loading of Circular Rings, Experimental Mechanics, Proceedings of the 11 th Annual Symposium, University of New Mexico, 1971, pp. 15-26.

17. H. Kolsky, Stress Waves in Solids, Dover, New York, 1963, Chapter 5. 
The key to computing the ring modal solution is the ability to calculate natural frequencies of vibration. This is done by assuming displacements of the form

$$
\left\{\begin{array}{c}
w_{0} \\
v_{0} \\
\phi_{0} \\
w_{c} \\
v_{c} \\
w_{i} \\
v_{i} \\
\phi_{i}
\end{array}\right\}=\left\{\begin{array}{lll}
\alpha_{1} & \cos n \theta \\
\alpha_{2} & \sin n \theta \\
\alpha_{3} & \sin n \theta \\
\alpha_{4} & \cos n \theta \\
\alpha_{5} & \sin n \theta \\
\alpha_{6} & \cos n \theta \\
\alpha_{7} & \sin n \theta \\
\alpha_{8} & \sin n \theta
\end{array}\right\} e^{i \omega t}
$$

Substituting this expression into the equations of motion, Equation (12), and setting the load vector to 0 yields a set of linear, homogeneous algebraic equations of the form

$$
\left[K\left(n, \omega^{2}\right)\right]\{\alpha\}=\{0\} .
$$

For a nontrivial solution, the determinant must vanish. The eight equations of motion require that the determinant of $\mathrm{K}$ be an eighth-order polynomial in $\omega^{2}$, i. e.,

$$
\operatorname{det} K=A \omega^{16}+B \omega^{14}+C \omega^{12}+D \omega^{10}+E \omega^{8}+F \omega^{6}+\mathrm{G} \omega^{4}+\mathrm{H} \omega^{2}+\mathrm{I}=0 \text {. }
$$

The coefficients, A to I, are complicated functions of the ring parameters and mode number $n$. It is not feasible to derive algebraic expressions for the coefficients but, for a given ring and a specific $n$, their numerical value can be computed. This is done by first evaluating the determinant of $K$ for $\omega=0$. Substituting this value into Equation (A3) gives $I=\operatorname{det} K(n, 0)$. Then eight other values of $\omega^{2}$ are chosen, and the determinant of $\mathrm{K}$ is computed for each. Substitution of these values into Equation (A3) results in eight simultaneous linear algebraic equations for the eight unknown coefficients $A$ through $H$. Solution of the equations yields numerical values for the coefficients of the characteristic polynomial, and standard algorithms can be used to find its roots. These roots are the natural frequencies. Amplitude ratios for each frequency are computed in the usual way by eliminating one equation from Equation (A2) and solving the resulting nonsingular set of equations. 
While this procedure is a bit indirect, theoretically it should work. Unfortunately, in practice, difficulties do arise. For one thing, the simultaneous equations used to solve for the characteristic polynomial coefficients are usually poorly conditioned and sometimes several sets of trial $\omega^{\prime} s$ must be chosen before the computation for the coefficients is successful. Once the roots of the characteristic equation are found, they should be substituted back into $\mathrm{K}$ and the determinant evaluated. Newton's method can then be used to refine the frequencies to the accuracy desired. 


\section{APPENDIX B}

Some basic background discussion is helpful in understanding the character of a solution that results from a higher order structural theory such as the theory derived in this report. Structural-type theories are developed to characterize the behavior of solids having at least one characteristic dimension much smaller than their other dimensions. These theories include time and the spatial variables whose axes lie along the larger dimensions of the structure as independent variables. The remaining spatial variables, whose axes are oriented along the smaller dimensions, do not appear as independent variables because of the theory's assumptions about the variation of displacement components with respect to these variables. It is the nature of these assumptions that determines how many dependent variables are included in the theory. For example, beam theory equations have the distance along the beam axis and time for independent variables. Elementary beam theory requires that plane sections remain plane and that normals to the neutral axis remain normal. With these assumptions the displacement of a cross section is characterized completely by one dependent variable $w$, the transverse displacement. Timoshenko beam theory relaxes the restriction on normals to the neutral axis remaining normal, with the result that an extra dependent variable $\phi$, the rotation angle of a cross section, is needed to specify completely the displacement. Note that the number of independent variables in a theory depends on the type of structure, but the number of dependent variables depends on the nature of the theory ${ }^{1} \mathrm{~s}$ assumptions. Thus, all beam and ring theories have one independent spatial variable and all plate and shell theories have two.

Free vibrations of structures can be characterized by their mode shapes, amplitude ratios, and frequencies. Here, mode shapes are understood to define the variation of displacements with respect to the independent spatial variables. For example, the $\operatorname{set}\{\sin n \pi x / \ell\}$ specifies the mode shapes of a simply supported beam. Amplitude ratios refer to the ratios of the amplitudes of different dependent variables for a particular frequency of vibration. Elementary ring theory has two dependent variables, the radial $\mathrm{w}$ and circumferential $\mathrm{v}$ displacements; and the amplitude ratio is $\mathrm{v} / \mathrm{w}$. In elementary shell theory, there is an additional (axial) displacement $u$ and two amplitude ratios, $\mathrm{u} / \mathrm{w}$ and $\mathrm{v} / \mathrm{w}$. For a given mode shape, a structural theory will yield as many frequencies of vibration as it has dependent variables. Each frequency corresponds to a different set of amplitude ratios. Thus, one mode shape can include several modes of vibration. The membrane and bending mode vibrations of elementary ring theory are an example. The mode shapes of the ring theory are $\{\sin n \theta$ and $\cos n \theta\}$. For a given mode shape, the membrane frequency is proportional to $\sqrt{\mathrm{n}^{2}+1}$, and its amplitude ratio $\mathrm{v} / \mathrm{w} \simeq \mathrm{n}$. The bending mode frequency is proportional to $n \sqrt{n^{2}-1} / \sqrt{n^{2}+1}$, and its corresponding amplitude ratio is $v / w \simeq-1 / n$. 
In general, the transient response of a linear structure to applied loads can be written in terms of a summation of its modes of vibration. To compute the solution, all that is required is to determine the extent to which each of the modes of vibration is excited (i. e., determine the modal coefficients) and the phase relationships of the modes. The degree of excitation for a particular mode depends upon how well the load distribution matches its mode shape and on how well the time variation of the load is tuned to the natural frequency; $i_{.} e_{.}$, how well the mode and load are matched in the time domain.

For the case at hand, Equation (20) of the text is a general expression for the modal coefficients of the three-layered ring solution. The summation from 1 to 8 on the index $k$ is the result of the fact that the theory contains 8 dependent variables and therefore each mode shape allows 8 different modes of vibration. The magnitude of $\ell_{j n}$ is a measure of how well the jth component of the load vector matches the nth mode shape. Similarly, the convolution integral is a measure of how well this particular component of the load is tuned to the $\omega_{\mathrm{kn}}$ frequency. Finally, the coefficient $M_{i j n}\left(-\omega_{k n}\right)$ contains information about the amplitude ratios of the ith component of displacement when the system is vibrating with the nth mode shape in the mode whose frequency is $\omega_{\mathrm{kn}}{ }^{\circ}$ 


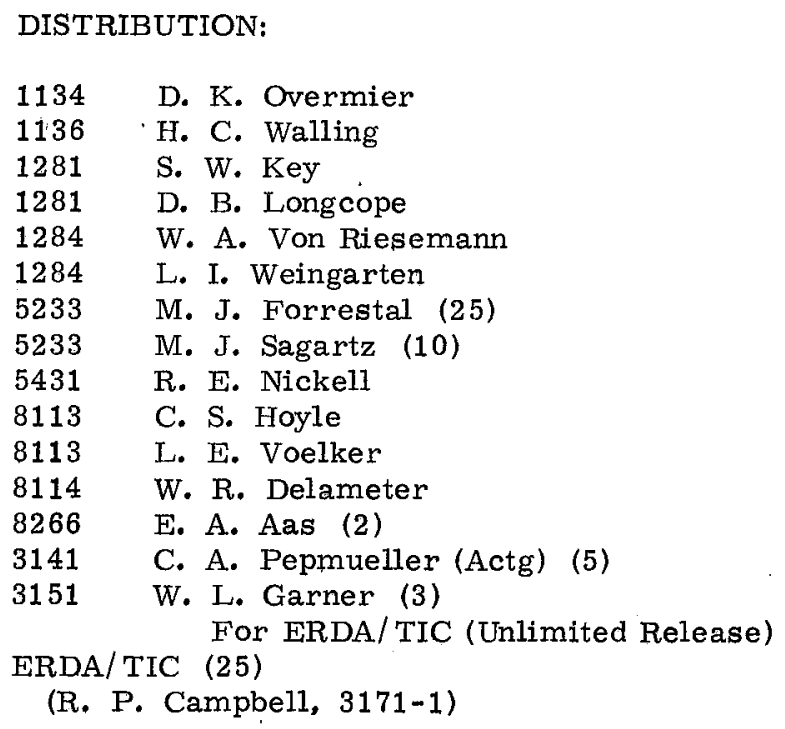

(R. P. Campbel1, 3171-1) 